\title{
High Resolution Ultrasonic Scanning of Animal and Human Tissue In Vivo
}
R. L. Roswell
R. E. Goans
J. H. Cantrell, Jr.

\section{OAK RIDGE NATIONAL LABORATORY}

OPERATED BY UNION CARBIDE CORPORATION FOR THE ENERGY RESEARCH AND DEVELOPMENT ADMINISTRATION 


\section{DISCLAIMER}

This report was prepared as an account of work sponsored by an agency of the United States Government. Neither the United States Government nor any agency Thereof, nor any of their employees, makes any warranty, express or implied, or assumes any legal liability or responsibility for the accuracy, completeness, or usefulness of any information, apparatus, product, or process disclosed, or represents that its use would not infringe privately owned rights. Reference herein to any specific commercial product, process, or service by trade name, trademark, manufacturer, or otherwise does not necessarily constitute or imply its endorsement, recommendation, or favoring by the United States Government or any agency thereof. The views and opinions of authors expressed herein do not necessarily state or reflect those of the United States Government or any agency thereof. 


\section{DISCLAIMER}

Portions of this document may be illegible in electronic image products. Images are produced from the best available original document. 


\section{Printed in the United States of America. Available from National Technical Information Service \\ U.S. Department of Commerce \\ 5285 Port Royal Road, Springfield, Virginia 22161 \\ Price: Printed Copy $\$ 5.50$; Microfiche $\$ 3.00$}

This report was prepared as an account of work sponsored by the United States Government. Neither the United States nor the Energy Research and Development Administration/United States Nuclear Regulatory Commission, nor any of their employees, nor any of their contractors, subcontractors, or their employees, makes any warranty, express or implied, or assumes any legal liability or responsibility for the accuracy, completeness or usefulness of any information, apparatus, product or process disclosed, or represents that its use would not infringe privately owned rights. 
Contract No. W-7405-eng-26

HIGH RESOLUTION ULTRASONIC SCANNING OF ANIMAL AND HUMAN

TISSUE IN-VIVO

R. L. Roswell, R. E. Goans, and J. H. Cantrell, Jr.
Submitted by R. L. Roswell to the Graduate Faculty
of Rensselaer Polytechnic Institute
in Partial Fulfillment of the
Requirements for the Degree of
Master of Science

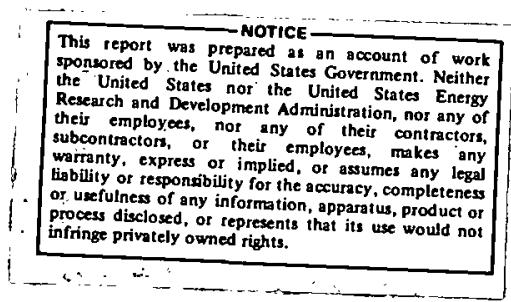

Date Published: August 1977

NOTICE This document contains information of a preliminary nature. It is subject to revision or correction and therefore does not represent a final report.

OAK RIDGE NATIONAL LABORAOTRY

Oak Ridge, Tennessee 37830

operated by

IINION CARBIDE CORPORATION

for the

ENERGY RESEARCH ANDD DEVELOPMENT ADMINISTRATION 


\section{THIS PAGE}

WAS INTENTIONALLY

LEFT BLANK 
TABLE OF CONTENTS

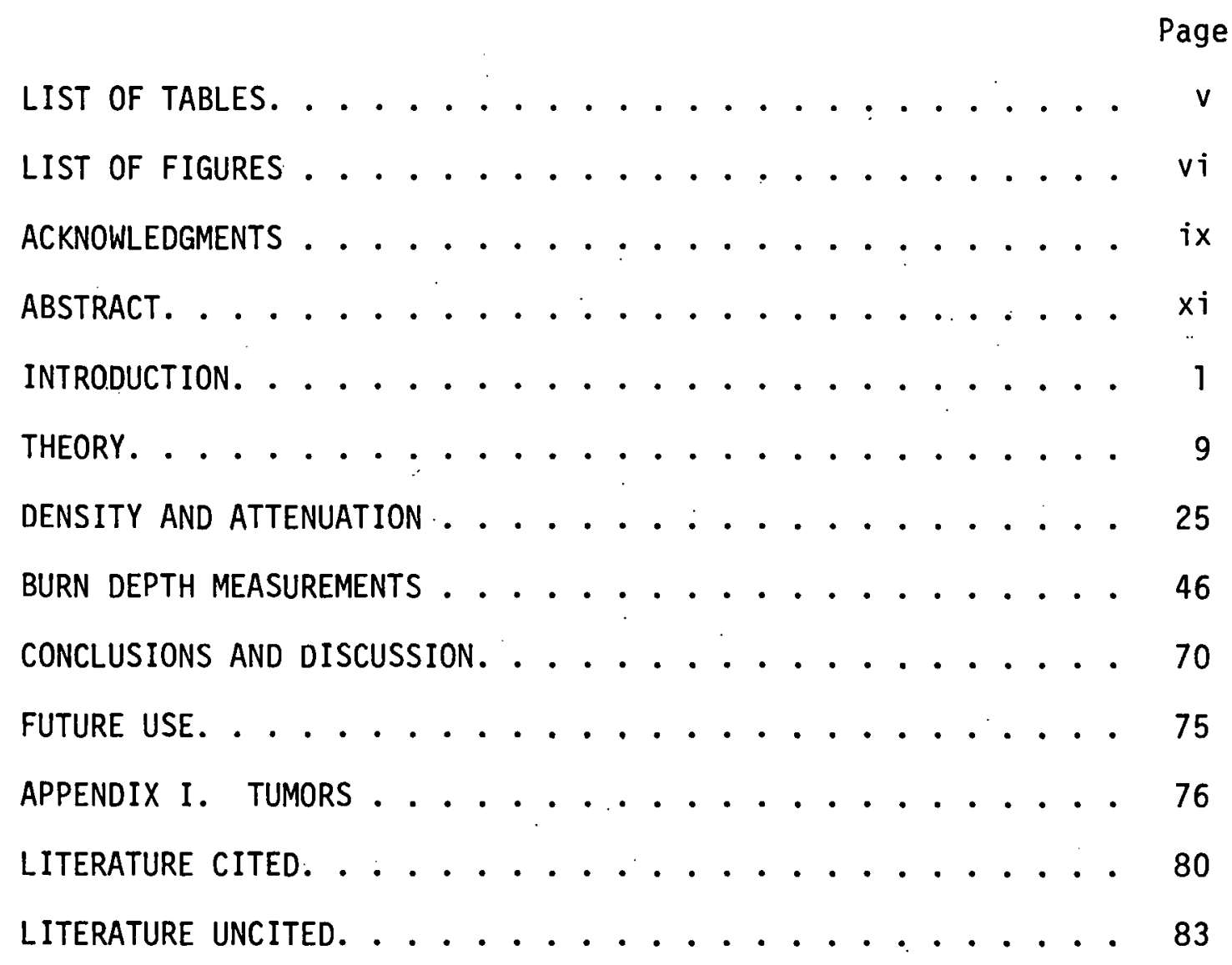




\section{THIS PAGE}

\section{WAS INTENTIONALLY LEFT BLANK}




\title{
LIST OF TABLES
}

\begin{abstract}
Page
Table I. Density Measurements. . . . . . . . . 28

Table II. Burn Data -- Slide Depth Versus Film Depth. . . . . 56

Table III. Burn Data -- Slide Depth Versus Film Depth. . . . 63
\end{abstract}




\section{LIST OF FIGURES}

Page

Figure 1. Layers of Skin. .............. 2

Figure 2. Burn Depth in Skin. ............. 4

Figure 3. Three Medium Case . . . . . . . . . . 17

Figure 4. Hysterises Loop of Absorption Process ....... 19

Figure 5. Electronics for Spectrum Analysis ....... 30

rigure G. R.r. Signal and Frequency Spectrum for Transduccrs. . 32

Figure 7. Transducer and Delay Line ........... 33

Figure 8. Frequency Spectrum -- Glass (10 MHz Transducer) ... 34

Figure 9. Frequency Spectrum -- Glass (2.25 MHz Transducer) . . 35

Figure 10. Frequency Spectrum -- Glass (10 MHz Transducer) . . . 36

Figure 11. Frequency Spectrum -- Aluminum (10 MHz Transducer). . 37

Figure 12. Frequency Spectrum -- Aluminum ( $15 \mathrm{MHz}$ Transducer). . 38

Figure 13. Frequency Spectrum -- Normal Tissue . . . . . . . 41

Figure 14. Frequency Spectrum -- Viable Tissue . . . . . . . 42

Figure 15. Frequency Spectrum -- Burned Tissue . . . . . . . 43

Figure 16. Electronics for U1trasonic Scanning . . . . . . . 47

Figure 17. Resolution Determination. .......... 49

Figure 18. Comparison of Scans with and without Delay Line Diaphragm ............ 51

Figure 19. Burning Irons ............... 52

Figure 20. Burn Depth for Several Burns. . . . . . . . . . 57

Figure 21. Scans of $30 \mathrm{sec}$ Burn Over Several Days. . . . . . 58

Figure 22. Burn Depth for Several Burns. . . . . . . . . 60

Figure 23. Burn Depth for Several Burns. . . . . . . . . 61 


\section{LIST OF FIGURES (CONT'D)}

Figure 24. Scans of $60 \mathrm{sec}$ Burn Over Several Days. . . . . . . 62

Figure 25. Histology Slide of Normal and Burned Porcine Skin . . . 64

Figure 26. Ultrasonic Scans of Wrist (Top Scan) and Hand

(Bottom Scan)............... 66

Figure 27. U1trasonic Scan of Human Chest

a. $1 \mathrm{~mm} /$ div, b. $5 \mathrm{~mm} / \mathrm{div}$........... 67

Figure 28. Two-Dimensional Scanner . . . . . . . . . . 69

Figure 29. Computer Drawn Three-Dimensional Plot. . . . . . . 71

Figure 30. Frequency Spectrum -- Burned Tissue . . . . . . . . 74

Figure 31. U1trasonic Scan of Rat Tumor

a. $1 \mathrm{~mm} /$ div. b. $5 \mathrm{~mm} /$ div ........ ..... 78 
THIS PAGE

WAS INTENTIONALLY

LEFT BLANK 


\section{ACKNOWLEDGMENTS}

The author wishes to express her sincere appreciation for the valuable guidance and support of Dr. J.W. Poston during the course of this research. Special acknowledgment and thanks go to B. A. Alenskis for his support and editorial assistance. Also, the author expresses her gratitude to Mrs. K. M. Branam for her expert technical assistance in preparing this manuscript.

Finally, the author wishes to acknowledge the staff at the Comparative Animal Research Laboratory who contributed to the performing of the animal experiments. In particular, thanks go to Dr. W. Kopp, Dr. G. R. Eisele, and Dr. H. E. Walburg.

This research was performed in the Health and Safety Research Division of the Oak Ridge National. Laboratory which is operated for the Energy Research and Development Administration by the Union Carbide Corporation, under appointment to the Laboratory Graduate Participation Program administered by Oak Ridge Associated Universities for the Energy Research and Development Administration. 


\section{THIS PAGE WAS INTENTIONALLY LEFT BLANK}




\section{ABSTRACT}

Burns impose one of the most serious injuries to the skin due to the organ's function within the body system and to the body as a whole. In an effort to better deal with the burn wound by the immediate excision and grafting of third degree burns, a high resolution ( $0.2 \mathrm{~mm})$ ultrasonic pulse-echo technique was developed for determining burn depth. The experimental subjects were Yorkshire pigs because of the histological similarity between human and porcine skin. Burn depths were readily identifiable immediately postburn with the ultrasonic techniques, as were general trends concerning the burn-viable and viable-fat interfaces. The tissue characteristics, density and acoustic attenuation, effecting the impedance mismatch at the burn-viable tissue interface were investigated. The methods of fluid displacements and specific gravities yielded density values, while spectrum analyses produced attenuation measurements for normal, viable and burned tissue samples. 


\section{CHAPTER I}

\section{INTRODUCTION}

The skin is one of the more important organs of the human body. Unlike other species, humans do not possess a protective armor such as secreted cuticles, massive scales, mucus or a dense layer of hair (Ro54). The skin is the exposed portion of the body which acts to maintain a constant internal environment, protect the body from various mechanical and chemical injuries, receive sensory stimuli, and provide for some exchange of gases, water and excretory products. In general, the skin is the external boundary which both inhibits and expedites "communication" between the body and the outside world.

Two major layers compose the skin: epidermis, and dermis (Figure 1). The epidermis is the outer, stratified epithelium providing the protective coating and is continually in a state of movement from inside out, being renewed and shed. A high degree of flexibility is combined with considerable mechanical strength in this layer. The dermis is a deep, thick layer of fibrous connective tissue. Blood vessels are abundant in this layer with some extending into the papilla-like projections of the dermis in the epidermis. These vessels perform nutritive functions as well as thermoregulation. Also within the dermis are nerves and other microscopic sensory organs which provide touch, pressure, temperature and pain sensations. Below the epidermis and dermis lies the fat layer. This fat is in the subcutaneous region and serves as a food reserve, thermal insulator and protection against mechanical injury (Vi73). Therefore, it is understandable that any injury 


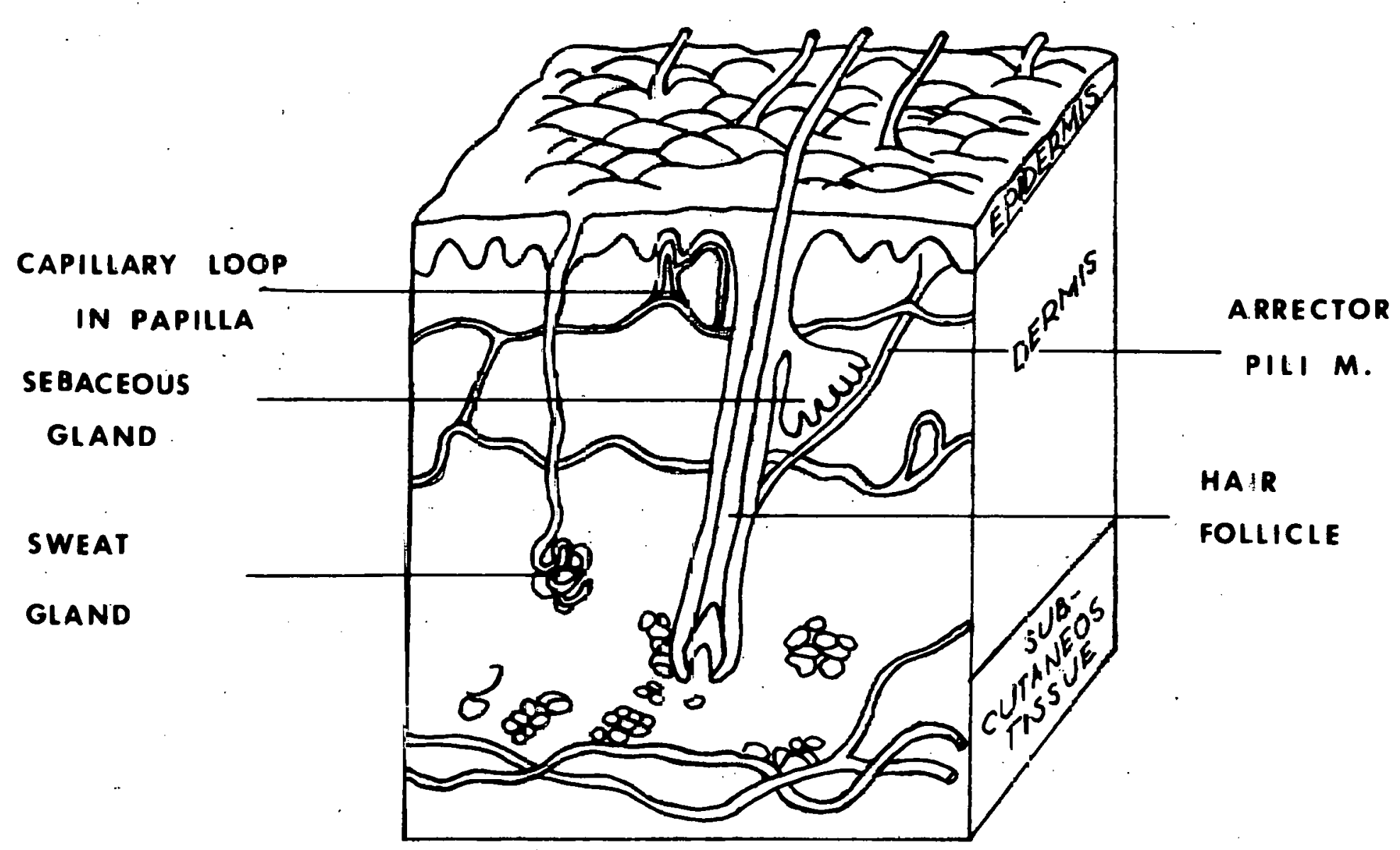

Figure 1. Layers of Skin. 
to the skin layers creates a hazardous situation for the whole body. One of the most severe types of injury to the skin, and consequently the whole body, is a burn. A full-thickness burn over $20 \%$ of the body produces a physiological effect similar to having one's legs crushed by a train (Ly73). Burns are also the most difficult injury to manage due to the unique placement and function of the skin within the body system and because damage may extend beyond the burn site.

Three classifications describe burn depth (Figure 2). A "first degree" burn only involves the epidermis with a slight erythema (reddening) and is touch-sensitive. A "second degree" burn penetrates the dermis and is characterized not only by an erythematous moist surface and touch sensitivity but also by blister formation. Both the first and second degree burn are partial-thickness burns and can, with time, repair themselves. A full-thickness burn, or "third degree" burn, goes below the dermis involving the subcutaneous tissue, and is characterized by a dry insensitive surface. Self-repair is impossible in third-degree burns. The percentage of total body surface area (BSA) involved in the burn describes the extent of the burn and is the most important factor in determining prognosis and treatment (Ar73).

With a full-thickness burn the protective coating of the body is completely destroyed, leading to observable pathophysiological events. These events may be caused by the effects of thermal injury on the skin, Weat injury to the blood vessels and blood elements, and general metabolic disturbances. Total destruction of the skin by thermal injury not only permits invasive infection to enter, sometimes causing the body temperature to rise, but also allows the loss of significant quantities of heat 
ORNL-DWG 76-4879

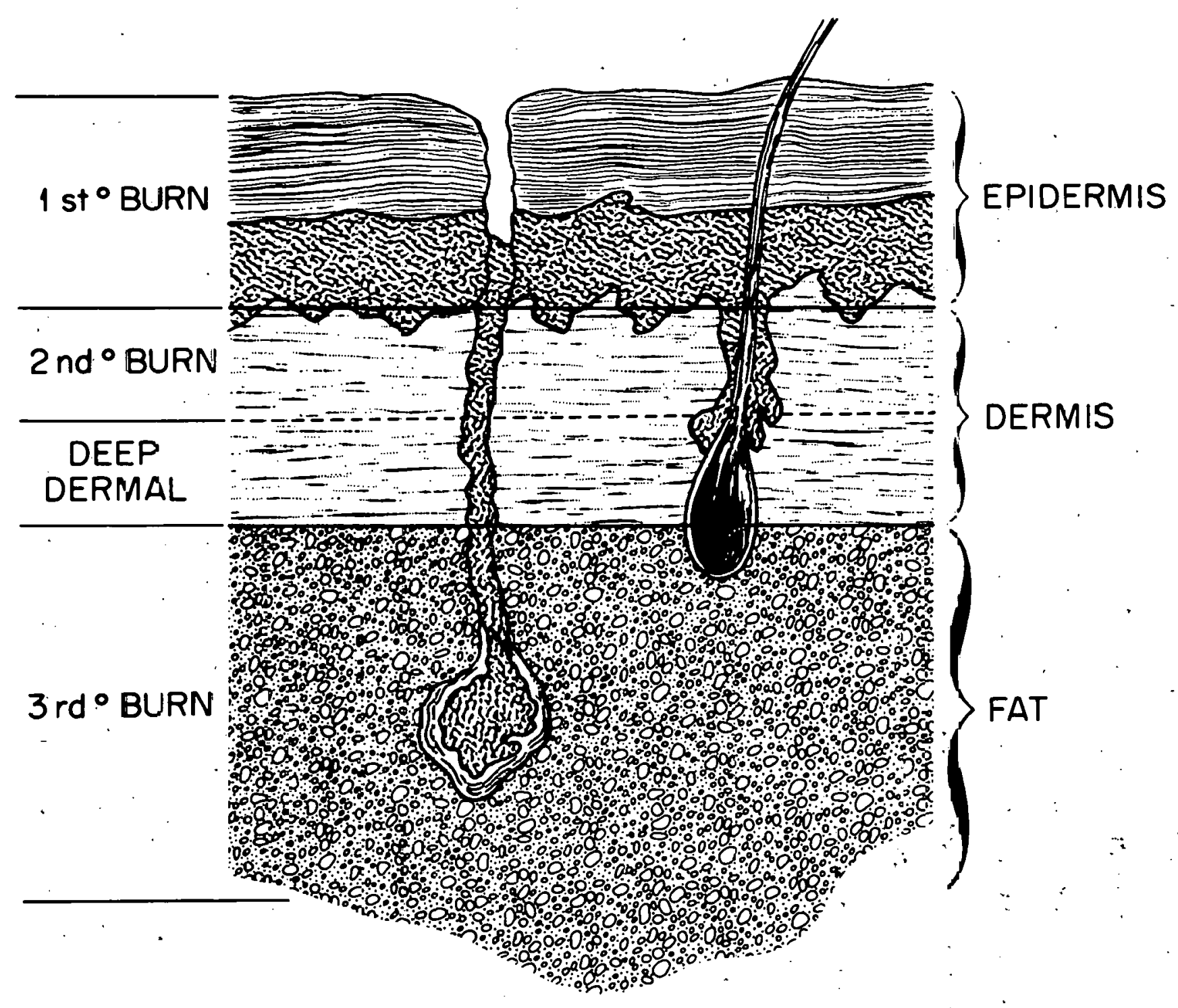

Figure 2. Burn Depth in Skin. 
and water. Fluid loss may reach as high as $200 \mathrm{ml} / \mathrm{m} 2 / \mathrm{hr}$ (Ar73), with the corresponding heat.loss. Fluids and proteins escape at a rapid rate from injured blood vessels which have lost their capillary integrity and therefore have increased their permeability. This fluid reduction results in a rapid decline in blood volume and the characteristic shock phase which appears within 48 hours after the burn. The loss of vital fluids upsets the blood chemistry and body metabolism, thus leading to the malfunction of the kidneys, heart and/or other vital organs. The lungs may be seriously involved when there has been inhalation of smoke, superheated air, etc. causing respiratory problems.

The first 48 hours post-burn are most critical for the burn patient. During this time an adequate airway and respiration must be insured, intravenous fluid therapy must be initiated to replace the lost body fluids and blood plasma and the extent of the body burn and its depth must be estimated. Many times there is evidence of circulatory impairment in the extremities. The cause may be edema beneath a tight unyielding eschar which exerts a tourniquet-like effect or with burns of the chest, a constrictive effect impairing respiration. In these cases, incisional decompression is obtained by cutting through the full-thickness eschar to the underlying fascia. After approximately 48 hours patient care changes in emphasis to three principals: maintenance of nutrition, prevention of infection, and closure of wound.

It is not surprising then that, for burn injuries, there is high morbidity and mortality. Considering nontransport accidents, in the age groups from 1 to 4 years and 45 years and older, burns are the leading cause of death. For children ages 5 to 14 years, burns are the second 
most common cause of death. In 1975, the National Fire Protection Association reported 11,800 fire deaths in the United States, while fire injuries totaled 131,000 (Me77).

Historically, the treatment of the burn wound has centered around controlling burn wound sepsis and obtaining early wound closure. Standard systemic antibiotics are ineffectual due to the destruction of the capillaries at the burn site. Instead, topical dressings uttlizing silver nitrate, silver sulfadiazine, or other sulfa compounds are applied to the burn, being changed on an hourly schedule dependent on the progress of the burn healing. Baths in Hubbard tanks on a daily basis help to remove dead tissue and provide an environment where the patient can undergo physical therapy. Patient movement is important for maintaining muscle tone and for showing the patient he can still be functional, an important psychological advantage.

With the removal of necrotic eschar and the appearance of viable granulation tissue, wound closure by split-thickness grafting is begun. The skin grafts are obtained from unburned portions of the patient's skin using a dermatone. For patients whose donor sites are not sufficient, cadaver allografts are applied. Donor sites are usually ready for reharvesting by the time the allografts are rejected. Heterographs using porcine skin may be used as a temporary wound covering if cadaver skin is unavailable.

The time required for the natural debridement of the dead eschar is considerable. In one study by Burke (Bu74), wound closure using the silver nitrate treatment required 45 days in patients with burns of $10 \%$ to $19 \%$ BSA, 75 days for patients with burns of 20\% to 39\% BSA, and 101 days for 
patients with burns of $40 \%$ to $65 \%$ BSA. In this same study Burke describes the method of primary excision and immediate grafting with continued use of silver nitrate. With this method of treatment the mortality statistics drop from $11 \%$ to $4 \%$. The number of days to obtain functional wound closure (a measure of the morbidity suffered by the patient) dropped for a.11 three categories: 30 days for 10\% to 19\% BSA, 40 days for patients with $20 \%$ to $39 \% \mathrm{BSA}$, and 62 days for $40 \%$ to $65 \% \mathrm{BSA}$. This is a significant decrease in time. Therefore, it appears that the patient would be far better off if the surgeon could differentiate self-repairing second degree from nonrepairing third degree burns. He then could remove the dead eschar surgically and perform immediate grafting while maintaining a topical agent regimen, rather than wait for natural debridement. To adopt this course of treatment, a fairly accurate knowledge of the burn depth is required.

The objectives of the research described in this thesis center around the need to characterize further tissue (both normal and burn) and to define accurately burn depths in skin. An ultrasonic pulse-echo method was selected as the means of investigation because there is a definite impedance mismatch between viable and nonviable tissue which gives a reflection at the burn boundary. Due to the similar histological nature of human and pig skin, young Yorkshire pigs became the experimental subjects for testing the ultrasonic method of burn depth determination. The technique was then extended for human use. The second objective of this work was to answer the question of what caused the impedance mismatch between the burned and viable skin tissue. With Fourier spectrum analysis, the characteristics of skin layer thicknesses and 
attenuation were measured, while a copper sulfate method for determining specific gravities was utilized to measure the density of the two sample types. A comparison of the values of attenuation and density for normal and burned skin answered this question. 


\section{CHAPTER II}

\section{THEORY}

Ultrasound consists of mechanical vibrational energy with frequencies above the normal range of human hearing, i.e. above $20 \mathrm{kHz}$. Like other energy wave forms, ultrasonic wave motion has frequency, wavelength, amplitude, velocity, pressure, and intensity. The wave also interacts with its environment which causes reflection, refraction, phase shifts, attenuation, and absorption. In propagating through a medium, the wave causes the particles of the medium to oscillate in various modes, and, depending on the type of motion, the nature of the wave can be characterized. Longitudinal waves occur when the particle motion is parallel to the direction of propagation. Propagation of these waves is possible in all types of media and is the basis for medical ultrasonic diagnostic techniques. Transverse waves, or shear waves, propagate particle motion perpendicular to the flow of energy. Fluids do not possess shear elasticity and therefore cannot support this type of motion. These waves are of little importance in diagnostic techniques.

Consider the propagation of a plane, non-spreading wave through a homogeneous medium. The particles of the medium follow simple harmonic motion and from the wave equation.

$$
\frac{\partial^{2} \xi}{\partial t^{2}}=c^{2} \frac{\partial^{2} \xi}{\partial z^{2}} \text { or } \frac{\partial^{2} p}{\partial t^{2}}=c^{2} \frac{\partial^{2} p}{\partial z^{2}}
$$

the parameters of particle displacement amplitude, velocity and acceleration can easily be found. They are 


$$
\begin{array}{ll}
\xi=\xi_{0} \sin \omega\left(t^{\prime}-z / c\right) & 2-2 \\
v=2 \pi f \xi_{0} \cos \omega(t-z / c) & 2-3 \\
a=-4 \pi^{2} f^{2} \xi_{0} \sin \omega(t-z / c) . & 2-4
\end{array}
$$

$\xi$ is the particle displacement, $c$ is the speed of propagation and $p$ is the excessive pressure. The phase angle of the wave is the quantity $(\omega(t=z / c))($ Hu7.5).

When considering how ultrasound interacts with various environments, the amount of energy transported through a unit of area per second is of importance. Another important consideration is some measure of the concentration of the rate of energy propagation--intensity, I. The intensity is given by the relation:

$$
I=2 \pi^{2} f^{2} \rho_{0} c \xi^{2}
$$

where $\rho_{0}$ is the density of the medium. This quantity involves controllable parameters of the wave, $f$ and $\xi$, and also a parameter of the medium, the characteristic acoustic impedance, $Z_{0}: Z_{0}$ is defined as the product $\rho_{0} c$. The characteristic acoustic impedance, as well as geometric factors, constitutes the specific acoustic impedance, $Z$. $Z$ is defined as $p / v$, the ratio of excessive pressure to particle velocity: For plane, longitudinal waves, $7=Z_{0}$ and $p / v=p_{0} c$.

In considering damped waves; the dissipative forces are proportional to the velocity of the particles, -Rv per unit volume, and must be considered in the wave equation,

$$
\frac{\partial^{2} \xi}{\partial t^{2}}+\frac{R}{\rho} \frac{\partial^{2} \xi}{\partial t^{2}}=c^{2} \frac{\partial^{2} \xi}{\partial x^{2}}
$$


Assuming a solution of the form

$$
\xi=A e^{i(\omega t+\gamma x)}
$$

where $\gamma$ is the propagațion constant, and substituting it into the wave equation yields

$$
-\omega^{2}+i \omega \frac{R}{\rho}=-c^{2} \gamma^{2}
$$

and

$$
\gamma= \pm k\left(1-i \frac{R}{\rho \omega}\right)^{\frac{1}{2}} \text {. }
$$

For small damping, the term $(1-i R / \rho \omega)^{\frac{3}{2}}$ can be expanded in a power series and if all but the first two terms are neglected, yields

$$
\gamma= \pm\left(k=i \frac{R}{2 \rho c}\right) .
$$

The displacement, $\xi$, then becomes

$$
\xi=A e^{-\alpha x} e^{i(\omega t-k x)}+B e^{\alpha x} e^{i(\omega t+k x)}
$$

where $k=\omega / c$ and $\alpha$ is the attenuation constant, equal to

$$
\alpha=R / 2 p c .
$$

In the positive direction of wave motion, the acoustic pressure of the damped wave is

$$
p=-\rho c^{2} \frac{\partial \xi}{\partial x}=\rho c^{2}(\alpha+i k) \xi,
$$

and the particle velocity is

$$
v=\frac{\partial \xi}{\partial t}=i \omega \xi \text {. }
$$

The specific acoustic impedance for this wave becomes

$$
z=p / v=\rho c(1-i \alpha / k) \text {. }
$$


The acoustic pressure in the damped wave lags behind the particle velocity by a phase angle, $\theta$, given by

$$
\tan \theta=\frac{\alpha}{k}=\frac{R}{2 \rho \omega} \cdot \therefore(K i 50) \quad 2-16
$$

Often it is necessary to compare two intensity levels, as in the measurement of absorption. Then it is advantageous to measure the ratio of pairs of intensities or amplitudes, particularly if the level of one of the pair is a reference point for comparison with other ratios. In this manner, the need for the measurement of absolute numbers is avoided, and measurements can be made electronically by expressing the amplitudes as ratios of voltages. If these ratios are expressed logarithmically, numbers extending over large orders of magnitudes can be expressed, and number manipulation is made easier--the arithmetic product of two or more quantities is obtained by the addition of their logarithms. The unit of the intensity ratio is the decibel and is defined as

$$
\begin{aligned}
\text { Power level } & =10 \log _{10} \mathrm{P}_{2} / \mathrm{P}_{1} \text { decibels. } \\
& =20 \log _{10} \mathrm{~A}_{2} / \mathrm{A}_{1} \text { decibels, }
\end{aligned}
$$

where $P$ is power and $A$ is amplitude.

When the medium supporting the wave is no longer homogeneous, the ultrasonic wave deviates from its path of propagation by reflection, refraction, dispersion, diffraction, or scattering. At a boundary between two different media, the wave is partially reflected, returning in the negative direction through the incident medium, and the rest of the wave is transmitted into the second medium, continuing in the positive 
direction. The velocity of the reflected wave will remain equal to the initial velocity, while the velocity of the transmitted portion will correspond to propagation in the second environment. As in optics, the laws of geometry hold for reflection. The angle of incidence equals the angle of reflection in the same plane, $\theta_{i}=\theta_{r}$, and by Snell's Law,

$$
\frac{\sin \theta_{i}}{\sin \theta_{t}}=\frac{c_{1}}{c_{2}}
$$

Also, the direction of the transmitted wave is refracted or bent toward or away from the normal to the interface depending on the velocities of propagation in the media.

At the boundary between the two media, a continuum is maintained. Therefore the total pressure across the boundary must be equal, and the velocity across the interface must be continuous. This ensures complete contact between the two media. It is the ratio of the particle pressure and the velocity--the impedance--which affects the reflection-transmission characteristics of the interface. If the impedances are equal the wave passes the interface unaffected by the environmental change. When the impedances are different, the initial energy is shared by the reflected and transmitted waves such that the equilibrium conditions are maintained. That is,

$$
\begin{gathered}
p_{i}+p_{r}=p_{t} \\
v_{i} \cos \theta_{i}-v_{r} \cos \theta_{r}=v_{t} \cos \theta_{t} .
\end{gathered}
$$

Velocity is a directional quantity, and therefore angle must be considered, whereas pressure is non-vectorial. Solving these two equations simultaneously yields the pressure reflectivity, $\mu_{r} / \dot{p}_{j}$, and the pressure trans- 
missivity, $p_{t} / p_{j}$. Knowing

$$
p_{0}=\rho c v_{0}
$$

and

$$
\text { - I }=\frac{1}{2} \mathrm{O} C v_{0}^{2},
$$

the substitution $I=\frac{1}{2} \mathrm{p}_{0}^{2} / \rho c$, can be made into the above expressions for reflectivity and transmissivity to obtain the intensity reflection coefficient and the intensity transmission coefficient, $\alpha_{r}$ and $\alpha_{t}$.

$$
\begin{aligned}
& \alpha_{r}=\left[\frac{z_{2} \cos \theta_{i}-z_{1} \cos \theta_{t}}{z_{2} \cos \theta_{i}+z_{1} \cos \theta_{t}}\right]^{2} \\
& \alpha_{t}=\frac{4 z_{2} z_{1} \cos ^{2} \theta_{i}}{\left(z_{2} \cos \theta_{i}+z_{1} \cos \theta_{t}\right)^{2}}
\end{aligned}
$$

At normal incidence or $\theta_{i}=\theta_{t}=0$, the above reduce to

$$
\begin{aligned}
& \alpha_{r}=\left[\frac{z_{2}-z_{1}}{z_{2}+z_{1}}\right]^{2} \\
& \alpha_{t}=\frac{4 z_{2} z_{1}}{\left(z_{2}+z_{1}\right)^{2}} ;
\end{aligned}
$$

If $Z_{1}=Z_{2}, \alpha_{r}=0$ and $\alpha_{t}=1$ and there is total transmisston (We69). If $Z_{1} \ll Z_{2}$, as at the interface between a liquid and a gas or between human soft tissue and bone, $\alpha_{r}$ approaches 1 , and almost complete reflection is obtained. The angle of incldence also determtnes if the wave is reflected. If incidence is at an angle greater than the critical angle, total reflection is achieved. Because ultrasonic waves can be reflected and refracted, they can be directed once they are produced 
and, in particular, they can be focused. An acoustic lens placed in front of the transducer can cause the ultrasonic beam to be gradually narrowed in its near-field by the process of refraction. The focusing places a greater intensity of energy at that area of material.

When the interface between two media of differing characteristic impedances is rough, or there is a small obstacle, the refraction and reflection equations above may not apply. Instead, there is a specular reflection with an additional scattered field energy, the amount of which is dependent upon the geometrical characteristics of the object discontinuities. Some of the ultrasonic wave is reflected over a wide range of angles, and some of the wave is refracted through the complex surface. An acoustical shadow also is formed behind the obstacle. The scattering contribution is mathematically described using Huygens principle of radiation--the incident wave, plus the radiation from Huygens sources on the scattering object, forms the sum. With the presence of a number of small objects (a rough surface), the beam is disrupted, as is the directivity of the source. As the dimensions of the obstacle approach the magnitude of the wavelength or less, the intensity of the reflected wave varies inversely as the fourth power of the wavelength (We69).

With the introduction of another layer and formation of a second interface, the problem of reflection and transmission becomes more complex (Se71). Partial reflection occurs at both boundaries and standing waves are set up in the first two layers. Both the reflection back into the first medium and the transmission into the third layer 
are controlled by the standing waves established in the second medium. At normal incidence (Figure 3 ), the wave in medium $1,(x=0)$, is represented by

$$
f_{1}=\Lambda_{i} e^{i\left(\omega t-k_{1} x\right)}+A_{r} e^{i\left(\omega t+k_{1} x\right)} .
$$

The wave in medium 2 has the same form

$$
f_{2}=B_{t} e^{i\left(\omega t-k_{2} x\right)}+B_{r} e^{i\left(\omega t+k_{2} x\right)}, x=L \text {. }
$$

Medium. 3 only has the transmitted part of the wave frunl medium 2 ,

$$
f_{3}=A_{t} e^{i\left(\omega t-k_{3}(x-L)\right)} .
$$

The A's and B's are the amplitudes of the waves, and $k_{1}=\omega / c_{1}, k_{2}=$ $\omega / c_{2}, k_{3}=\omega / c_{3}$ are the wave numbers.

As stated previously, at the boundaries, steady state conditions provide two boundary conditions: (1) the acoustic pressures at both sides of the interface are equal, and (2) the velocities normal to the interface are equal. Given these two ronditions and the wave equations above, the intensity transmission coefficient for a "lossless" medid can be found.

$$
\alpha_{t}=\frac{4 Z_{3} Z_{1}}{\left(Z_{3}+Z_{1}\right)^{2} \cos ^{2} k_{2} L+\left(Z_{2}+\frac{Z_{3} Z_{1}}{Z_{2}}\right)^{2} \sin ^{2} k_{2} L} \cdot \quad 2-30
$$

Medium 3 is assumed to be infinite.

The characteristics of the second medium control, to a large extent, the effects in the surrounding layers. Only when $L$ is much less than a quarter wavelength or an integral number of half wavelengths is 
ORNL-DWG 77-7726R

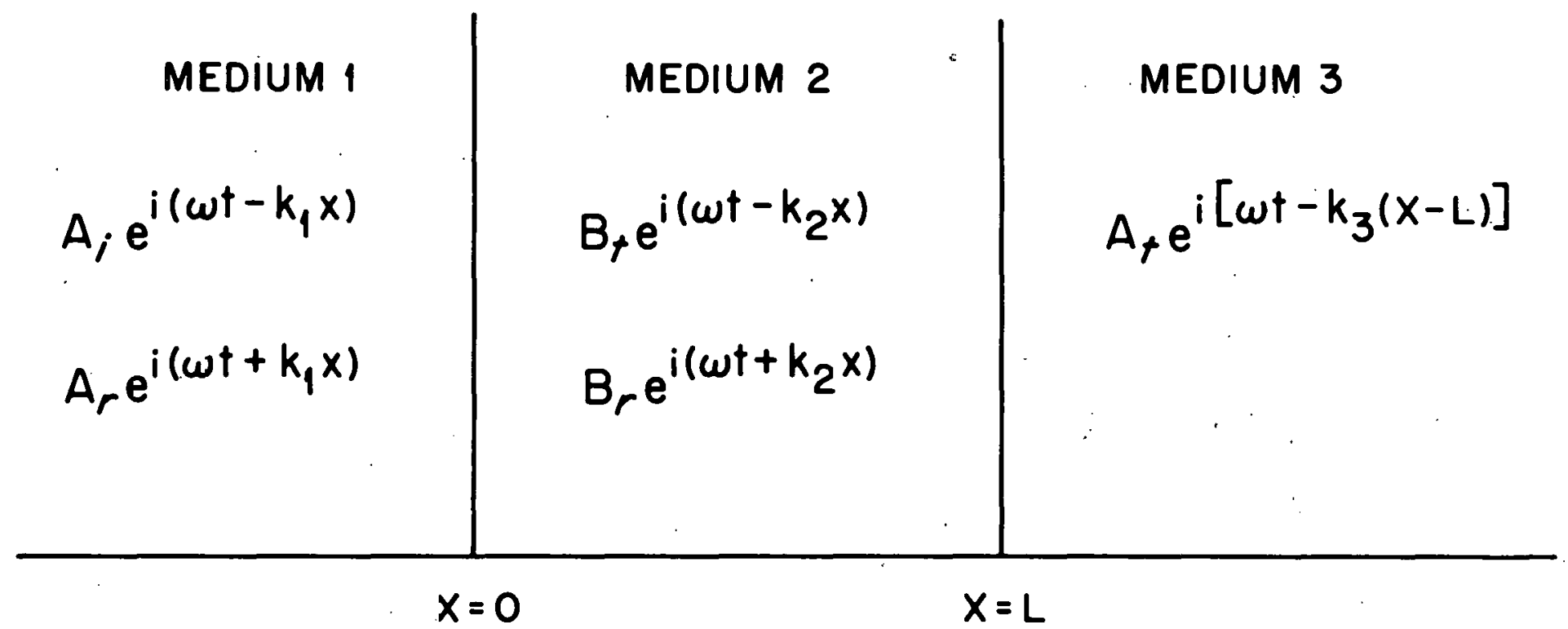

Figure 3. Three Medium Case. 
transmission independent of the properties of the second layer. If $Z_{2}$ is very small compared to $Z_{1}$ and $Z_{3}$ (if there is a gas layer trapped between two materials), then $Z_{1} Z_{3} / Z_{2}$ becomes very large, and transmission is greatly reduced. When the second medium has a characteristic impedance that is the geometric mean of the first and third layers, $Z_{2}=\sqrt{Z_{1} Z_{3}}$, and the thickness of the second medium is an odd integral number of quarter wavelengths, $\alpha_{t}$ becomes unit. Therefore, it is possible to obtain total transmission, but the process is frequency-dependent..

In passing through a material, the ultrasonic wave is attenuated. Several mechanisms contribute to the attenuation of the wave. One mechanism is a result of the deviation from a parallel beam. The energy per unit area is reduced. Scattering from elastic discontinuities also serves to attenuate the ultrasonic beam, because the discontinuity acts as a reflecting surface. As described previously, this discontinuity scatters the beam from the original direction of propagation, producing attenuation.

Two processes of attenuation actually involve the absorption of ultrasonic energy into the supporting medium. One absorption process is determined by viscosity and heat conduction. The viscosity of the fluid opposes the vibrational motion of the particles, and therefore some of the wave energy is converted to heat. The lag between the pressure and density of the medium is controlled by the time required for heat conduction to occur from high to low pressure regions of the field, and it is this lag which accounts for the energy absorption. Work is done on the system with heat as the product absorbed in the medium. Figure 4 (Hu75) is a graphic explanation of this phenomena. Line 1 corresponds to the condensation phase and the area below the curve is a measure of the condensation 


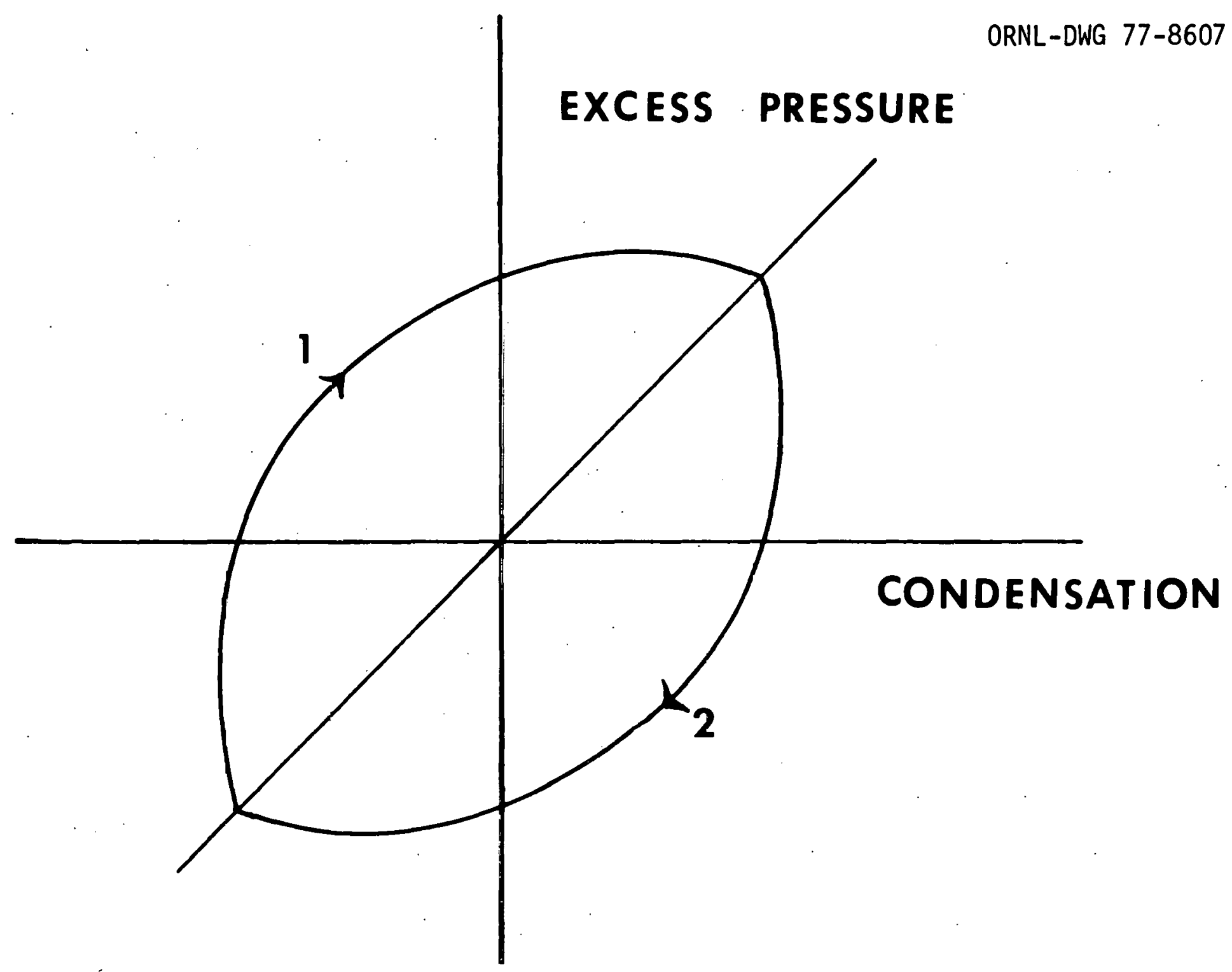

Figure 4. Hysterises Loop of Absorption Process. 
work. Line 2 represents the rarefraction stage with the area under the curve being a measure of the recovered work in the cycle. The area between the lines corresponds to the work in the system lost to heat.

The second process of absorption occurs because of the various forms in which energy may exist in a molecular system, be it molecular. vibrational energy, lattice vibrational energy, translational energy, etc. As the ultrasonic wave passes through the medium, there is translational motion of the particles. Energy is transferred frnm this translational mode to another mode, such as rotation, and then returned to the wave cycle at some later time. This is the relaxation process--energy is removed from the wave and returned later. Energy loss occurs when there is a phase lag between the energy flowing out and returning. The translational motion of the ultrasonic wave is opposed by the translational motions returned to the system from the transfer. The proportion of translational energy which is shared by the other modes and the magnitude of relaxation process time constants determine the energy loss. In soft-tissues, the attenuation of ultrasonic waves is rather complicated. But it appears that the relaxation processes in the protein constitute the major portion of absorption (We72). These processes follow a linear relationship between the absorption coefficient and frequency. Ti:e time delay in energy transfer at low frequencies is minimal, allowing absorption to be small. With increasing frequency, absorption increases until a maximum is attained where the shared energies are exactly opposed. With further increases of frequency, the time available for energy transfer is reduced, decreasing the absorption of energy into the particles of the media. 
Frequency analysis can be used extensively to measure the thickness of a sample and the attenuation of an ultrasonic wave in the medium ( $\mathrm{Si} 74$ ). It is known that an electrical signal and its associated frequency spectrum form a Fourier transport pair. It then is assumed that the observed spectrum is a direct consequence of the above relation. Broad-band sources are utilized and two or more reflections from the acoustic field are gated into the spectrum analyzer.

By definition, the Fourier transform of a time domain signal, $f(t)$, is

$$
F(\omega)=\int_{-\infty}^{\infty} f(t) e^{-i \omega t} d t
$$

In the experimental case of finite time, equation 2-31 is written

$$
F(\omega)=\int_{-T}^{T} f(t) e^{-i \omega t} d t=G(f(t)),
$$

where $f(t)$ is centered about $t=0$ and of duration 2T. G signifies the Fourier transform.

If a pulse signal, $f(t)$, of duration $2 T$ is input into the spectrum analyzer, the analyzer displays the magnitude of the Fourier transform of $f(t)$ :

$$
\mid G(f t))|=| F(\omega) \mid \text {. }
$$

With the addition of a second pulse delayed by $2 t_{0}$; the spectrum displayed by the analyzer now becomes

$$
\begin{aligned}
\left|G\left(f\left(t+t_{0}\right)+f\left(t-t_{0}\right)\right)\right| & =\mid e^{i \omega t_{O F}(\omega)+e^{-i \omega t} O F(\omega) \mid} \\
& =\left|2 \cos \omega t_{0}\right||F(\omega)| .
\end{aligned}
$$


This result arises from a Fourier analysis theorem that states if the Fourier transform of $f(t)$ is $F(w)$, then the transform of $f\left(t-t_{0}\right)$ is

$$
G\left(f\left(t-t_{0}\right)\right)=e^{-i \omega t_{0}} F(\omega) \text {. }
$$

In comparing equations $2-33$ and 2-34, the envelope of the resulting spectrum is similar to the spectrum for a single pulse, except there are maxima and minima which depend on $t_{0}$. The separation between maxima is

$$
\Delta f=1 / 2 t_{0}=1 / \Delta t
$$

With this expression and knowing the velocity of the ultrasonic wave in the medium, the thickness of a sample can be measured by gating into the spectrum analyzer the reflected pulse from the near surface and the reflected signal from the far surface.

As mentioned previously, the attenuation of an ultrasonic wave propagating through a medium is generally frequency dependent. If $f_{1}(t)$ is the front surface reflection, $f_{2}(t)$ is the back surface reflection, and $F_{2}(\omega)=k(\omega) F_{1}(\omega)$, then the resultant gated spectrum of both pulses is

$$
\begin{aligned}
\mid G\left(f_{1}\left(t+t_{0}\right)\right. & \left.+f_{2}\left(t-t_{0}\right)\right)|=| e^{i \omega t_{O} F(\omega)+k(\omega) e^{-i \omega t_{O}} F(\omega) \mid} \\
& =\left((1-k(\omega))^{2}+4 k(\omega) \cos ^{2} \omega t_{0}\right)^{\frac{1}{2}}|F(\omega)| .
\end{aligned}
$$

When there is no attenuation, $k(\omega)=1$, equation $2-37$ reduces to equation 2-34. With complete absorption of the wave, $k(\omega)=0$, the resultant spectrum is the front surface spectrum. If $0<k(\omega)<1$, the spectrum is similar to that of equation 2-34. The attenuation at the frequency of each peak is determined by finding the "modulation fraction" (ratio of 
minimum to maximum) and equating it to the ratio of the minimum and maximum of the square root term of equation 2-37.

At the boundary between two media, there may be a phase shift between the two input signals. This causes equation 2-34 to become

$$
\left|G\left(f\left(t+t_{0}\right)+e^{ \pm i \phi} f\left(t-t_{0}\right)\right)\right|=\left|2 \cos \left(\omega t_{0} \mp \phi / 2\right)\right| .|F(\omega)| .2-38
$$

The maxima no longer occur at intervals of $\Delta f$ but rather

$$
f_{n}=(n \pm \phi / 2 \pi) / \Delta t, n=0,1,2, \ldots
$$

The phase shift is then determined by measuring $\Delta f$ and $\Delta t$ and solving for $\phi$. The phase shift is dependent on the acoustic impedances of the two media and therefore is important in the measurement of the attenuation.

To obtain the attenuation measurements for the research described in this thesis, the above equations were utilized in another form ( $L i 76)$. Given $E_{1}(\omega)$ as the spectrum of the echo from the front surface,

$$
E_{1}(\omega)=\rho_{1} P(\omega),
$$

where $\rho_{1}$ is the pressure reflection coefficient, and $P(\omega)$ is the spectrum of the pulse if it were totally reflected from the surface. For slidil values of $\rho_{1}$, the back surface echo spectrum becomes

$$
E_{2}(\omega)=\rho_{2} P(\omega) e^{-2 \alpha 1 / c_{e}-i 2 \omega 1 / c},
$$

where 1 is the sample thickness, $\alpha$ is the sample absorptivity in nepers $(\mu s)^{-1}$, and $c$ is the wave velocity. The ratio of $E_{1}(\omega)$ and $E_{2}(\omega)$ el iminates $P(\omega)$ from consideration and gives 


$$
E_{1}(\omega) / E_{2}(\omega)=\left(\rho_{2} / \rho_{1}\right) e^{-2 \alpha 1 / c} e^{-i 2 \omega 1 / c} . \quad 2-42
$$

The magnitude of the ratio, $R(\omega)$, expressed in decibels yields

$$
20 \log R(\omega)=20 \log \left(\rho_{2} / \rho_{1}\right)-17.4 \alpha 1 / c, \quad 2-43
$$

or, with some manipulation,

$$
\alpha=\frac{\log E_{1}(\omega)-\log E_{2}(\omega)}{f_{2}-f_{1}} \quad \frac{20}{17.4 T} . \quad 2-44
$$

Thus: the attenuation of the sample (ignoring phase shifts) can be measured. 


\section{CHAPTER III}

\section{DENSITY AND ATTENUATION}

One of the objectives of the research presented in this thesis was to determine why an impedance mismatch occurs at the interface between viable and non-viable tissue in a burn wound. The minimum detectable mismatch between the impedances appears to be approximately $1 \%$ (Go77). Previous work (Ca76,Go77) showed that the velocity of sound in both normal and necrotic porcine tissue was approximately equal $( \pm 5 \%)$ at a value of $\sim 1720 \pm 45 \cdot \mathrm{m} / \mathrm{sec}$. Initial experiments on human eschar gave a value of $\sim 1540 \mathrm{~m} / \mathrm{sec}$, which was the currently accepted value for the velocity of sound in soft tissue. From Chapter II, it was known that the impedance, $Z$, was dependent on the wave velocity, the medium density and the attenuation of the wave in the medium,

$$
Z=\rho c(1-i \alpha / k)
$$

where

$$
\alpha=R / 2 \rho C \text { and } k=\omega / C \text {. }
$$

Because the velocities of the two types of tissue being considered were assumed to be equal, it was apparent that the impedance mismatch must be caused by a density change or an attenuation change from the burned layer to the viable layer, or possibly both.

In attempting to measure the density of burned pigskin, two methods were employed. Both experiments utilized burned and normal plugs of skin ( $\frac{1}{2}$ inch in diameter and approximately $\frac{1}{2}$ inch in depth) taken from 
the pig. The burned portions were removed from the center of each burn made on the back of the pig. The normal sections were removed from unburned areas of skin adjacent to where the burns were located. All burning times were $45 \mathrm{sec}$ at $100^{\circ} \mathrm{C}$. The details of the procedures involved in the burning of a pig are described elsewhere in this thesis.

The first method of density determination utilized the principle of fluid displacement. The mass of a small piece of skin was determincd (to four significant figures, i.e. $\pm 1 \mu$ ymi) on a metric balance. The sample was then placed in a tuberculin syringe containing a known amount of water. The volume displacement was measured and the density was calculated from

$$
\rho=m / v \text {, }
$$

where $m$ is the mass of the sample and $v$ is the sample volume.

The second method for determining the densities of the viable and necrotic tissue utilized copper sulfate solutions of differing specific gravities (Lu50). The solutions, made from $\mathrm{CuSO}_{4} \cdot 5 \mathrm{H}_{2} \mathrm{O}$, were prepared ylelding specific gravities varying from 1.0032 to 1.1020 in increments of $\sim 0.005 .$. The specific gravity, and therefore the density, was bracketed by a float/no-float test in the sample solutions. The bracket was obtained when the sample sank in one solution but floated in the next.

Both methods for density determination yielded similar results. From the mass and volume displacement method, the density for burn tissue was . found to be $1.082 \mathrm{gm} / \mathrm{ml} \pm 0.14$. Normal tissue yielded a density value of $0.998 \mathrm{gm} / \mathrm{ml} \pm 0.196$, which agrees reasonably well with the accepted 
value of approximately $1 \mathrm{gm} / \mathrm{cm}^{3}$ for soft tissue (MIRD69). Published values for burned skin density are not available. The fluid displacement method proved not to be as precise as was desired. When the tissue was forced down the tuberculin tube, capillary action would force water up the sides of the plunger. This amount of water was significant enough to affect the measurements. It was decided also, that the normal tissue was not a true example of the tissue underlying the burned layer. In tissue below the burn, there was some small amount of damage, but not enough to bring on necrosis. Therefore, dermis tissue immediately below the burned layer was tested in the experiments and labeled "viable" rather than "normal".

The copper sulfate method yielded the following specific gravities: normal, $1.0981 \pm 0.006$; viable, $1.0828 \pm 0.011$; burned, $1.0901 \pm$ 0.008 . Using $0.99823 \mathrm{gm} / \mathrm{ml}$ for the density of water at $20^{\circ} \mathrm{C}$, the average densities for normal, viable, and burned tissue were calculated to be $1.0961 \mathrm{gm} / \mathrm{cm}^{3}, 1.0808 \mathrm{gm} / \mathrm{cm}^{3}$, and $1.0882 \mathrm{gm} / \mathrm{cm}^{3}$, respectively (Table I). The characteristic impedances were calculated; the mismatch between viable and burned tissue was less than $1 \%$, while the mismatch for normal versus burned tissue was $1 \%$. Based on these results, it was concluded that the density variation between the burned and viable tissue was not significant enough to produce the boundary interface between the tissue layers.

A possible explanation for this lack of density change might lie in the fact that edema was produced in the burn wound. The burned skin is extremely porous to water vapor, and there is an increased 
Table I. Density Measurements

\begin{tabular}{lccc} 
Tissue & $\begin{array}{c}\text { Sperifir } \\
\text { Gravity }\end{array}$ & Density & $\begin{array}{c}\text { Density by Fluid } \\
\text { Displacement }\end{array}$ \\
\hline Normal & $1.0981 \pm 0.006$ & 1.0961 & $0.998 \pm 0.196$ \\
Viable & $1.0828 \pm 0.011$ & 1.0808 & \\
Burned & $1.0901 \pm 0.008$ & 1.0882 & $1.082 \pm 0.14$
\end{tabular}


rate of "insensible transcutaneous water vapor loss through the burn wound." The majority of the water loss is sequestered locally and not lost to the environment (Wa73). Therefore, while the structure of how the water is contained in the tissue is different for burned and normal tissue (normal tissue contains the fluid in cells, burned tissue holds free fluid), both types of tissue have a considerable amount of water.

Fourier spectrum analysis was the method utilized to determine the attenuation of the porcine skin specimens. Before measurements on the skin were made, solid samples of aluminum, brass, copper, glass and lucite were analyzed for thickness and attenuation to test the system. Figure 5 shows, in block form, the apparatus used for these experiments. The Panametrics pulse-receiver (Model 5052 PR) provided the "main bang" signal for the transducer, causing an ultrasonic pulse to be generated and transmitted into the sample. The reflected pulse, or echo, was received by the transducer and hence the pulser-receiver. The reflected echo was then sent into the Panametrics stepless gate (Model $5052 \mathrm{G}$ ) in order that a selectable portion of the wave could be gated for analysis. The Hewlett-Packard spectrum analyzer (Model HP 8557A) received the gated signal and displayed the Fourier spectrum of the pulse. An oscilloscope was connected to the pulser-receiver and gate to simultaneously view the unregulated echo pattern from the sample and also the gated portion of the pattern. Once a suitable spectrum appeared on the analyzer, a hard copy of the spectrum was drawn by an $X-Y$ recorder. The spectra from both the front surface and back surface reflections were placed on the same graph for analysis. When sample thickness 


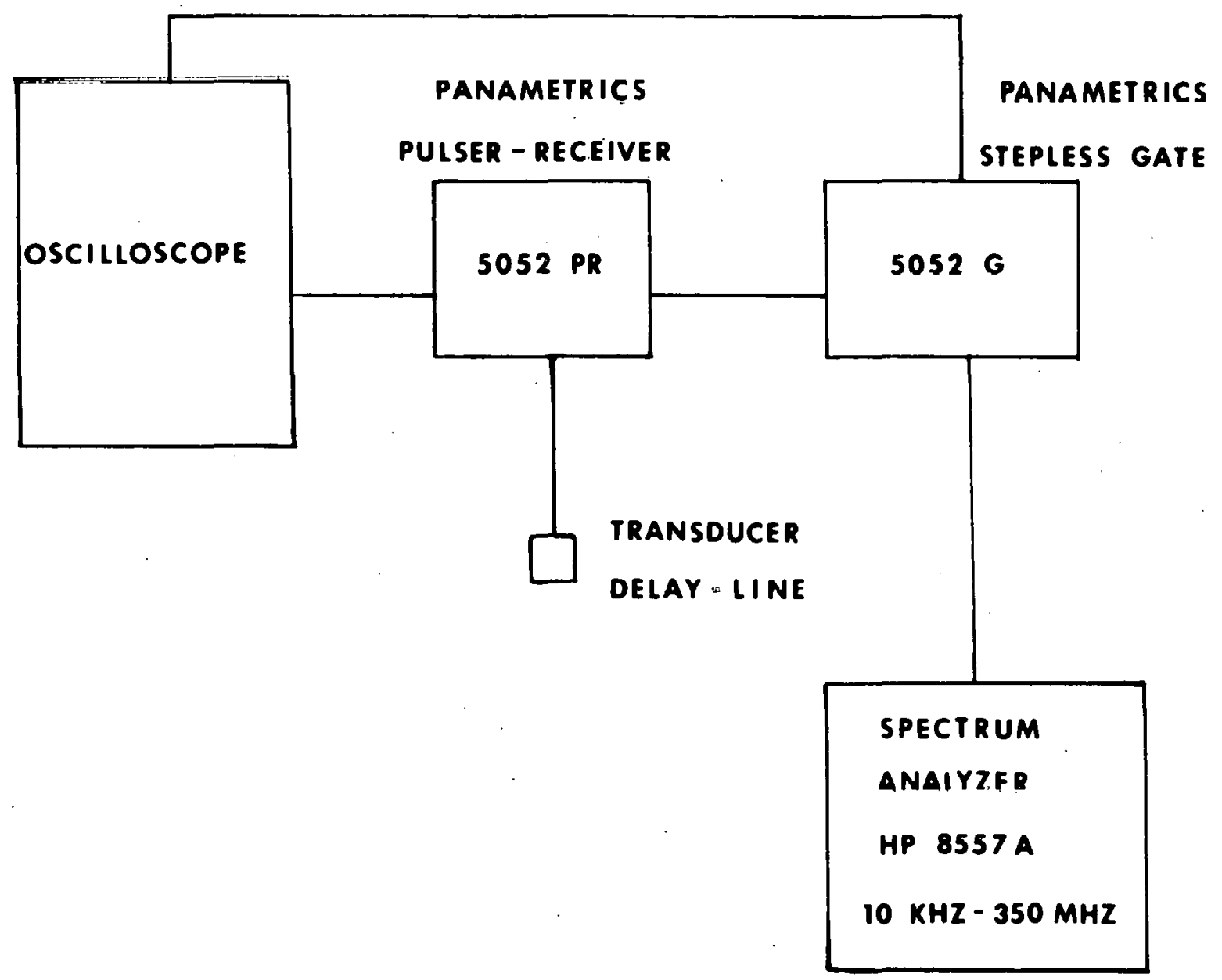

Figure 5. Electronics for Spectrum Analysis. 
was being determined also, these plots were traced with the reflection spectra. Figures 8 to 12 illustrate this procedure.

Panametrics transducers of various frequencies $(2.25 \mathrm{MHz}$ to $15 \mathrm{MHz}$ ) were tested on each sample to provide a range of frequency response. Each transducer utilized the piezoelectric effect and its inverse to convert electrical energy into mechanical energy and back again. Damping of the transducers enabled narrow pulses to be produced, thereby causing broadbanded frequency characteristics. Figure 6 displays for comparison the r.f. signal and frequency spectrum for each transducer used in the experiments. The more narrow the ultrasonic pulse, the broader the frequency content of the transducer.

In order to remove the front surface echo from the "mainbang" (the initial electrical signal pulsing the transducer) on the display, a delay line was constructed. The delay line was a cylindrical lucite tube approximately $15 \mathrm{~mm}$ in length and $13 \mathrm{~mm}$ inside diameter (Figure 7). The transducer fit into a hole in the cap which could be screwed on the tube. The delay line then was filled with an acoustical coupling gel and placed on the sample to be measured.

When sufficient coupling was obtained (no air bubbles between the transducer and the sample surface), three spectra were studied. The reflection from the top surface was shaped by energy input, attenuation and damping in the pulser-receiver, gated into the spectrum analyzer, and traced on the $X-Y$ recorder. The echo from the bottom surface then was gated into the analyzer with no further shaping and traced on the same graph. The third spectrum came from gating both the top reflection 


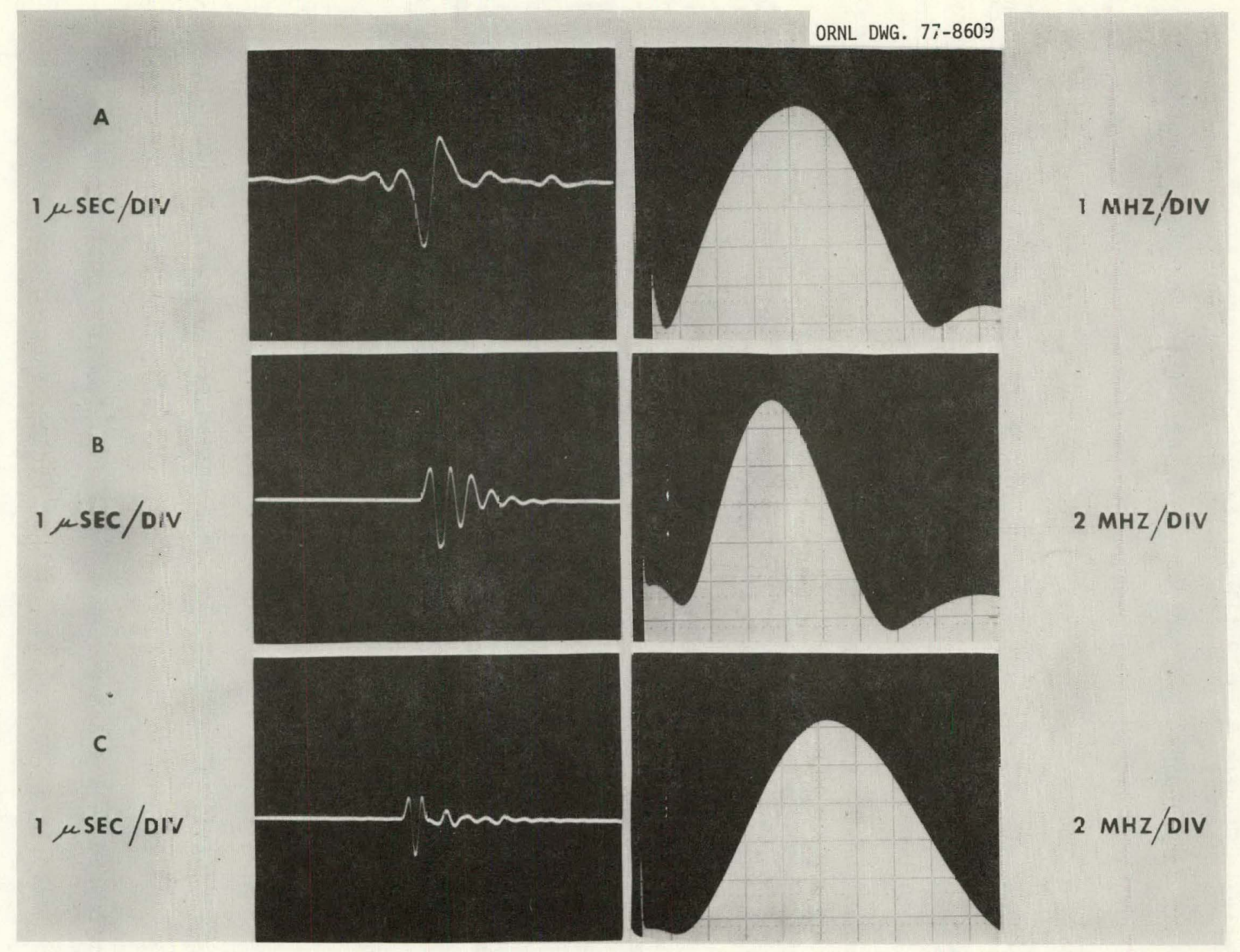

Figure 6. R.F. Signal and Frequency Spectrum for Transducers. 


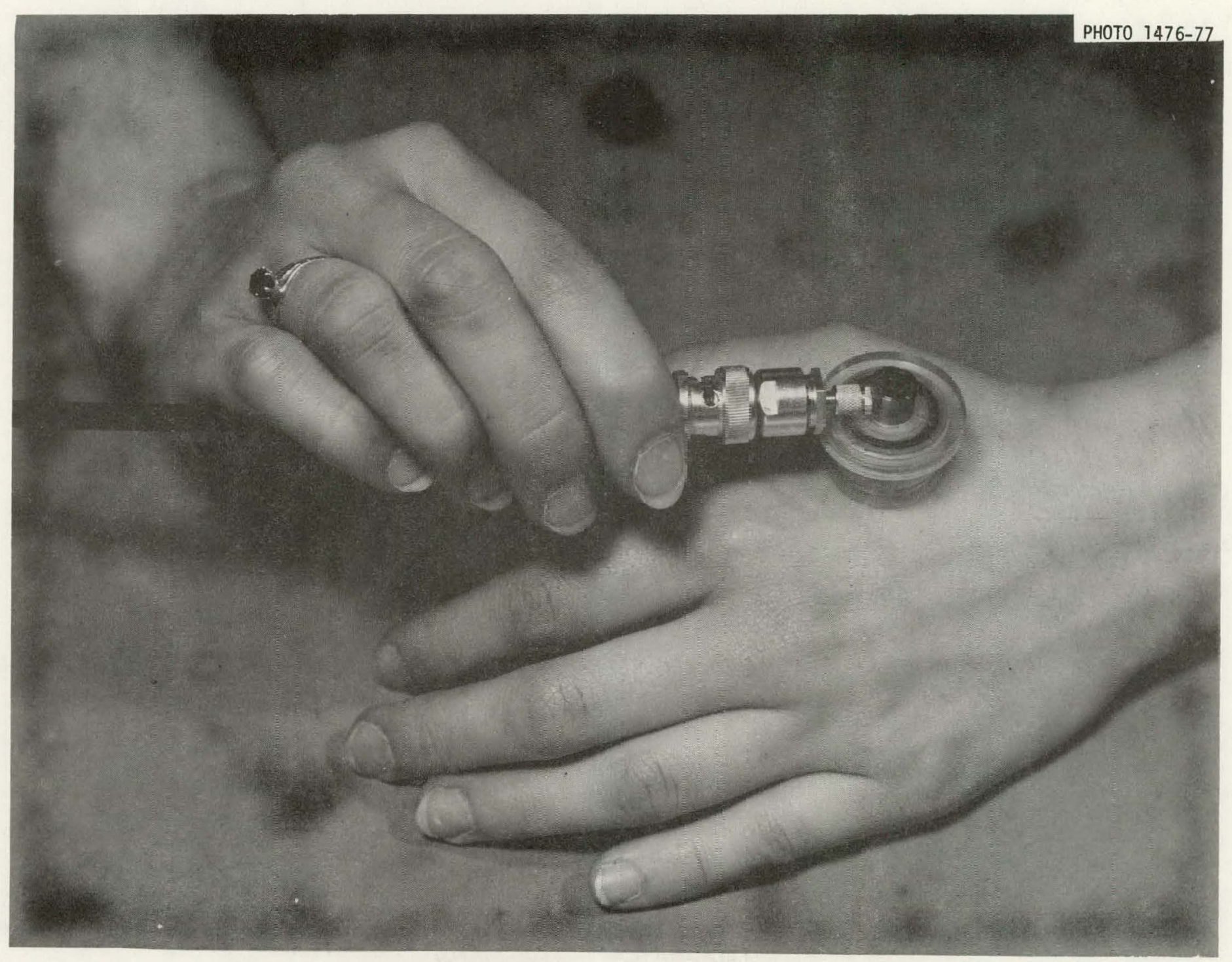

Figure 7. Transducer and Delay Line. 

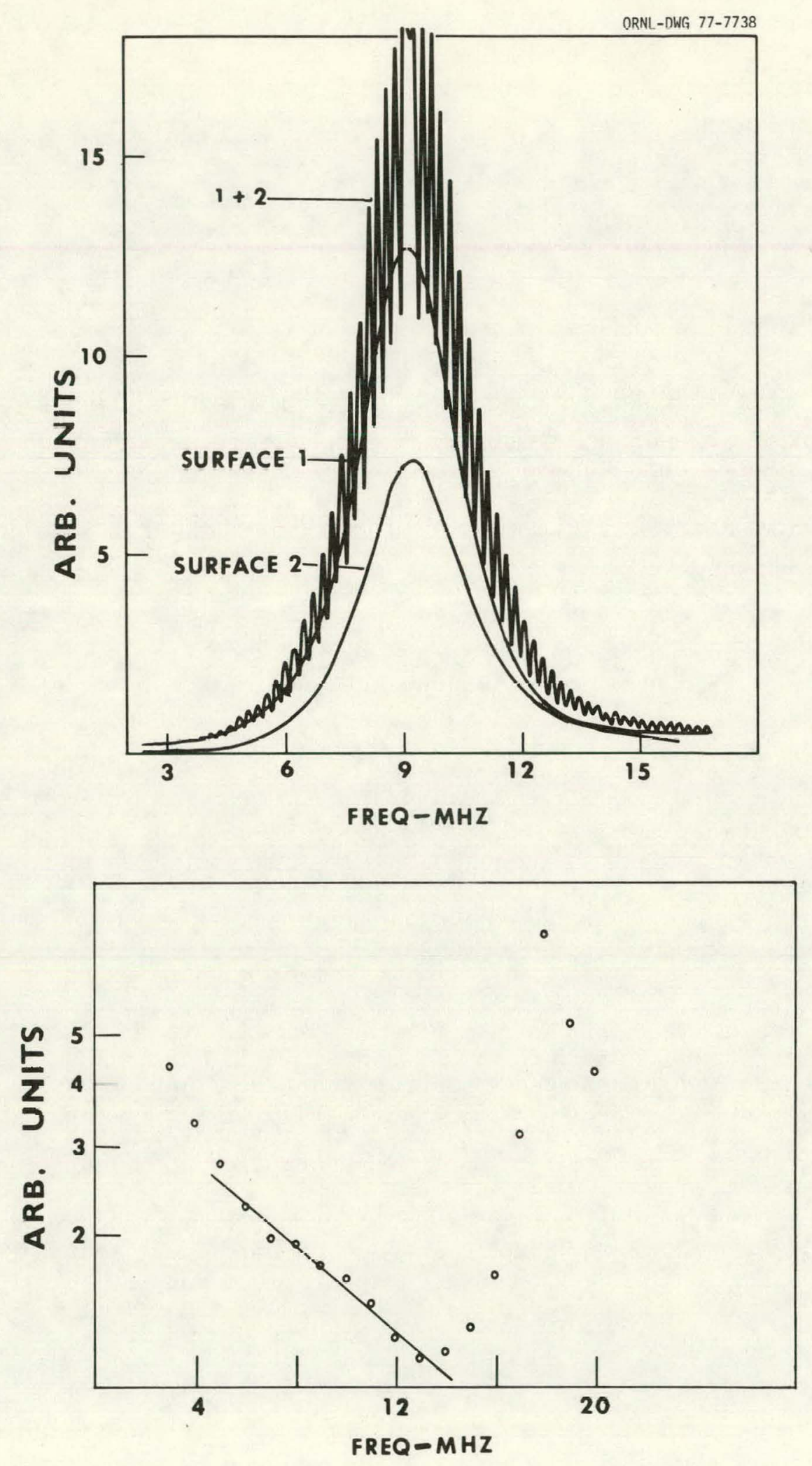

Figure 8. Frequency Spectrum -- Glass (10 MHz Transducer). 

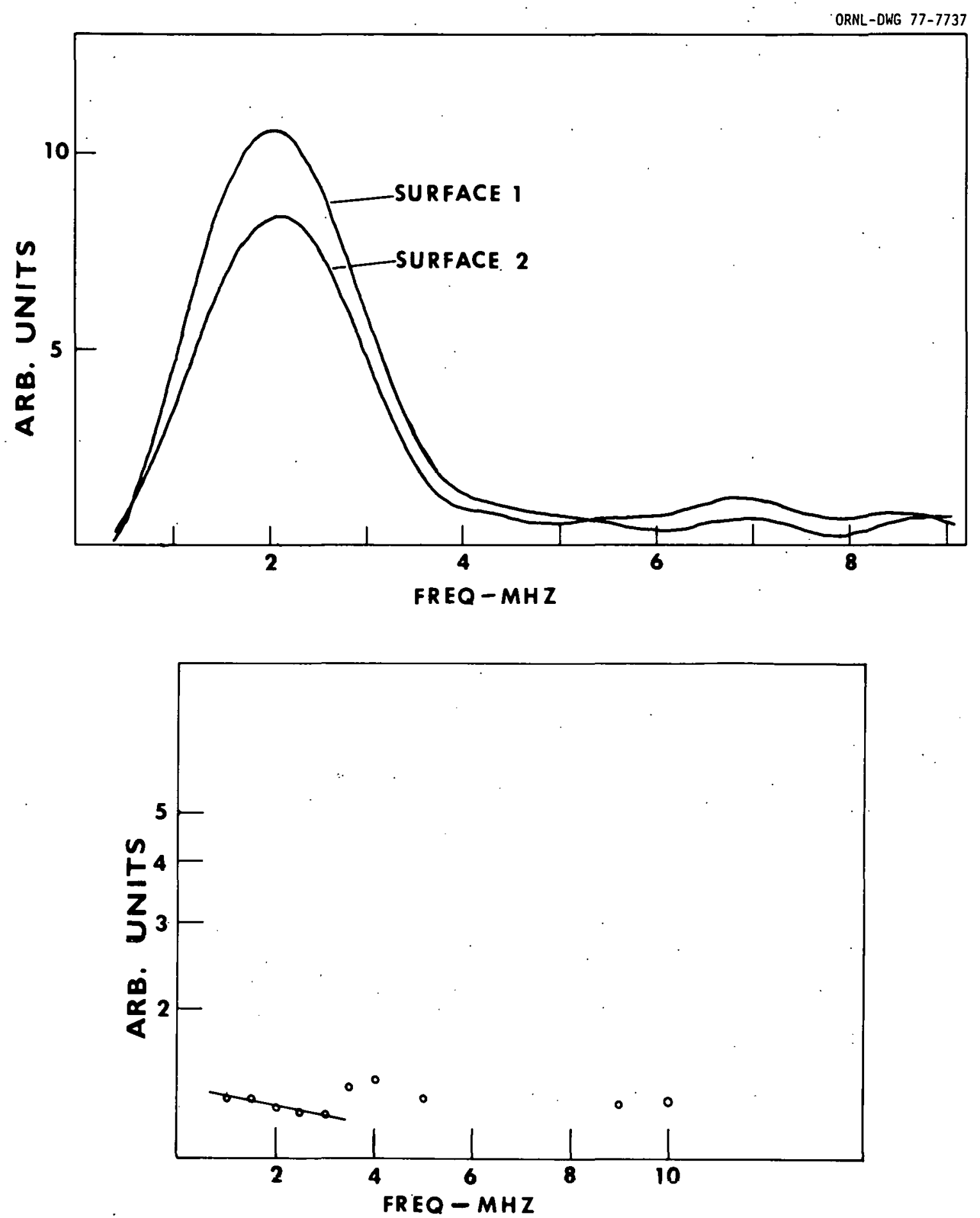

Figure 9. Frequency Spectrum -- Glass (2.25 MHz Transducer). 

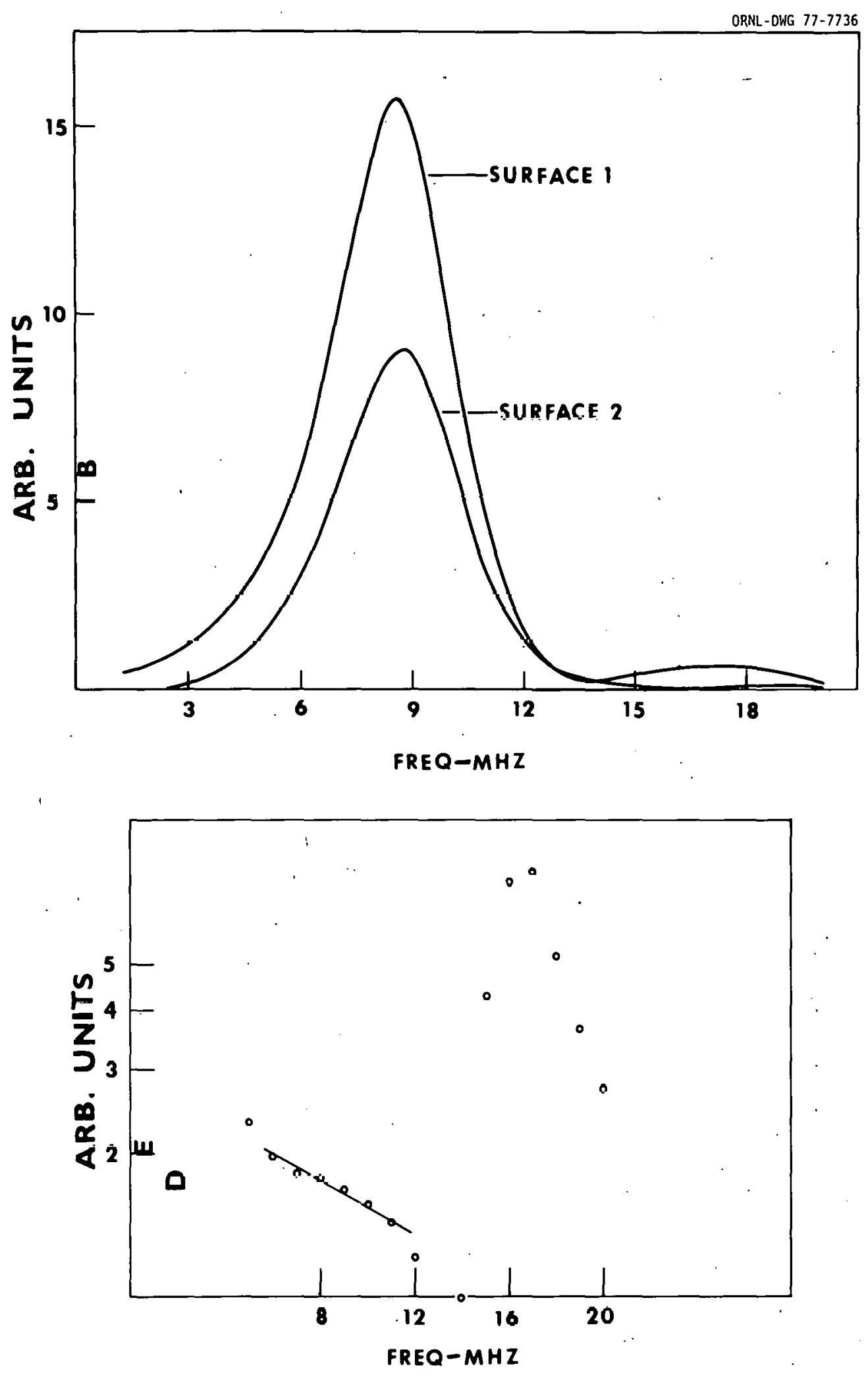

Figure 10. Frequency Spectrum -- Glass (10 MHz Transdicer). 

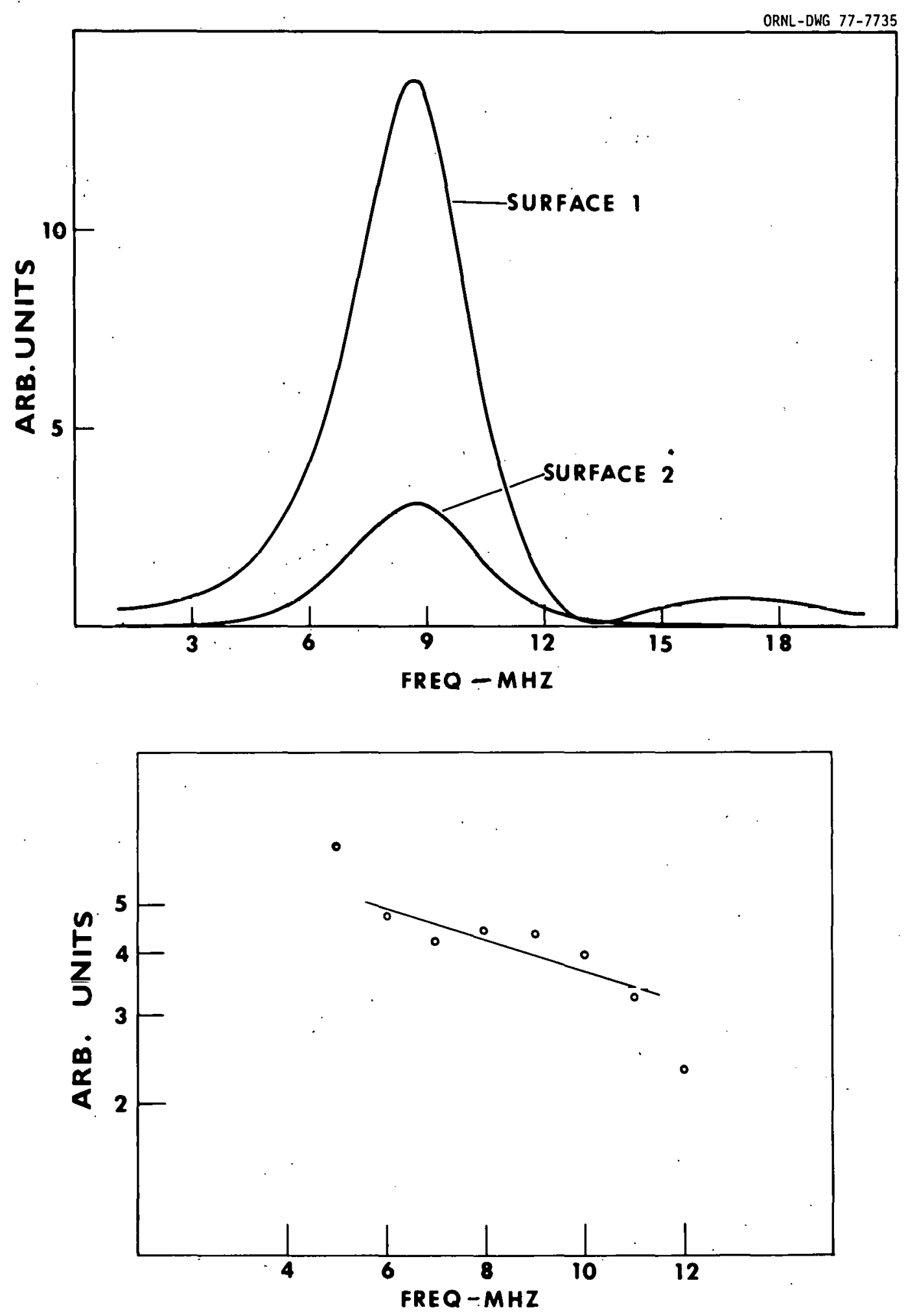

Figure 11. Frequency Spectrum -- Aluminum (10 MHz Transducer). 

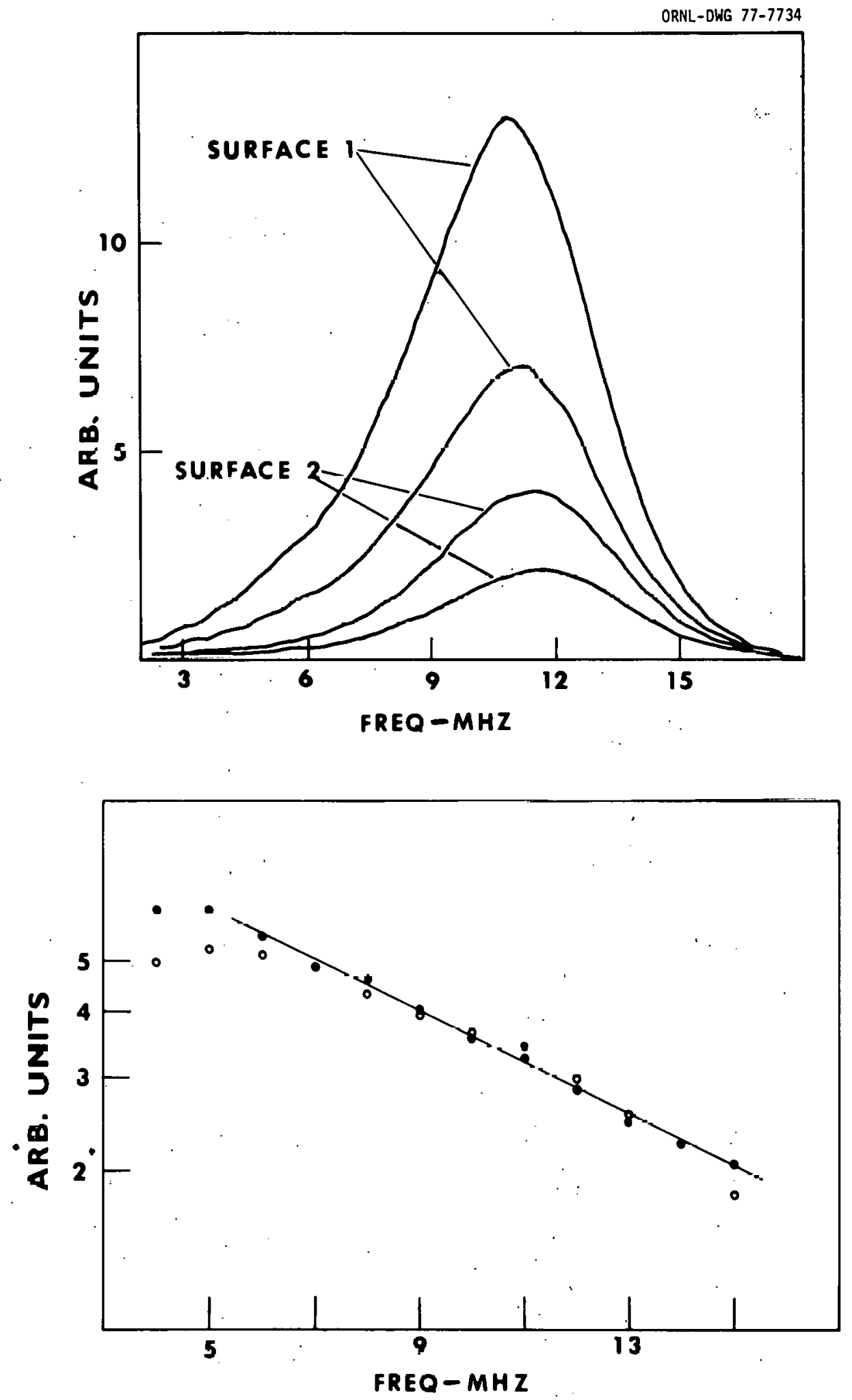

Figure 12. Frequency Spectrum -- Aluminum (15 MHz Transducer). 
and bottom reflection into the analyzer simultaneously, causing a superposition of the two reflections. This spectrum was used for thickness calculations, while the first two spectra yielded the attenuation information according to the equations 2-36 and 2-44, respectively. Figure 8 gives representative graphs used to calculate sample thickness. The sample was a block of glass manufactured to a depth of exactly $1.27 \mathrm{~cm}$. A $10 \mathrm{MHz}$ transducer provided the ultrasonic waves. The graph is a good example of how the superposition of the two reflection spectra follows the same shape as one individual spectrum with the addition of modulations. The number of minima over a four $\mathrm{MHz}$ range were counted to obtain $\Delta f$, and knowing the velocity of sound in glass to be $v=5.96$ $\times 10^{5} \mathrm{~cm} / \mathrm{sec}$, the thickness was calculated to be $1.27 \mathrm{~cm}$. This consistency existed through all thickness measurements.

Figures 9 to 12 are examples of spectra taken of glass and aluminum with transducers of differing frequency. Also shown are the plots of the ratios of the spectrum amplitude versus frequency on semi-log paper from which the attenuation results are calculated from equation 244. With the different transducers, the frequency response shifts, and it is only in the area of the center frequency of the transducer that the calculated plot line becomes straight. A published value for the attenuation of glass (crown) is $0.02 \mathrm{~dB} / \mathrm{cm}$ (Ka66) at $10 \mathrm{MHz}$, while for. aluminum the attenuation is $0.018 \mathrm{~dB} / \mathrm{cm}$ at $1 \mathrm{MHz}$. The experimental values obtained in our tests were $0.018 \mathrm{~dB} / \mathrm{cm}$ at $2.25 \mathrm{MHz}$ and 0.026 $\mathrm{dB} / \mathrm{cm}$ at $10 \mathrm{MHz}$ for glass, and for aluminum, $0.013 \mathrm{~dB} / \mathrm{cm}$ at $10 \mathrm{MHz}$ and $0.021 \mathrm{~dB} / \mathrm{cm}$ at $15 \mathrm{MHz}$. From these results it was concluded that the 
experimental system could determine ultrasonic wave attenuation in the samples. Subsequentiy, the attenuation of burned, viable and normal pig skin was measured.

Only one change was made in the experimental set-up for measuring the attenuation of porcine skin. Instead of using the delay line, a column of acoustical gel was placed on the plug of tissue, and left free standing with the transducer immersed in the top of the column. The dimension of the inner diameter of the delay line was approximately equal lo the dfameter of the tissue sample; a stable situation could not be attained otherwise.

The graphs for burn tissue were obtained by analyzing the reflections from the epidermis-burn interface. To view the viable tissue, all of the fat layer was excised from the under side of the skin plug. The transducer then was placed on this side of the plug, and the reflections from the dermis and burned interface were gated into the spectrum analyzer. The plots of the normal tissue were reflections from the epidermis and fat layers. All measurements utilized a $15 \mathrm{MHz}$ transducer.

Figures 13 to 15 show the spectra of normal, viable and burned pig tissues, respectively. Also shown are the plots of the amplitude ratio versus frequency. The accepted value for soft-tissue attenuation in humans is approximately $0.8 \mathrm{~dB} / \mathrm{cm}-\mathrm{MHz}$. From the graphs in Figure 13, the experimental value for attenuation in pig skin was calculated to be $0.73 \mathrm{~dB} / \mathrm{cm}-\mathrm{MHz}$ which is in general agreement with the human skin attenuation value. The experimental values for viable tissue and burned tissue 

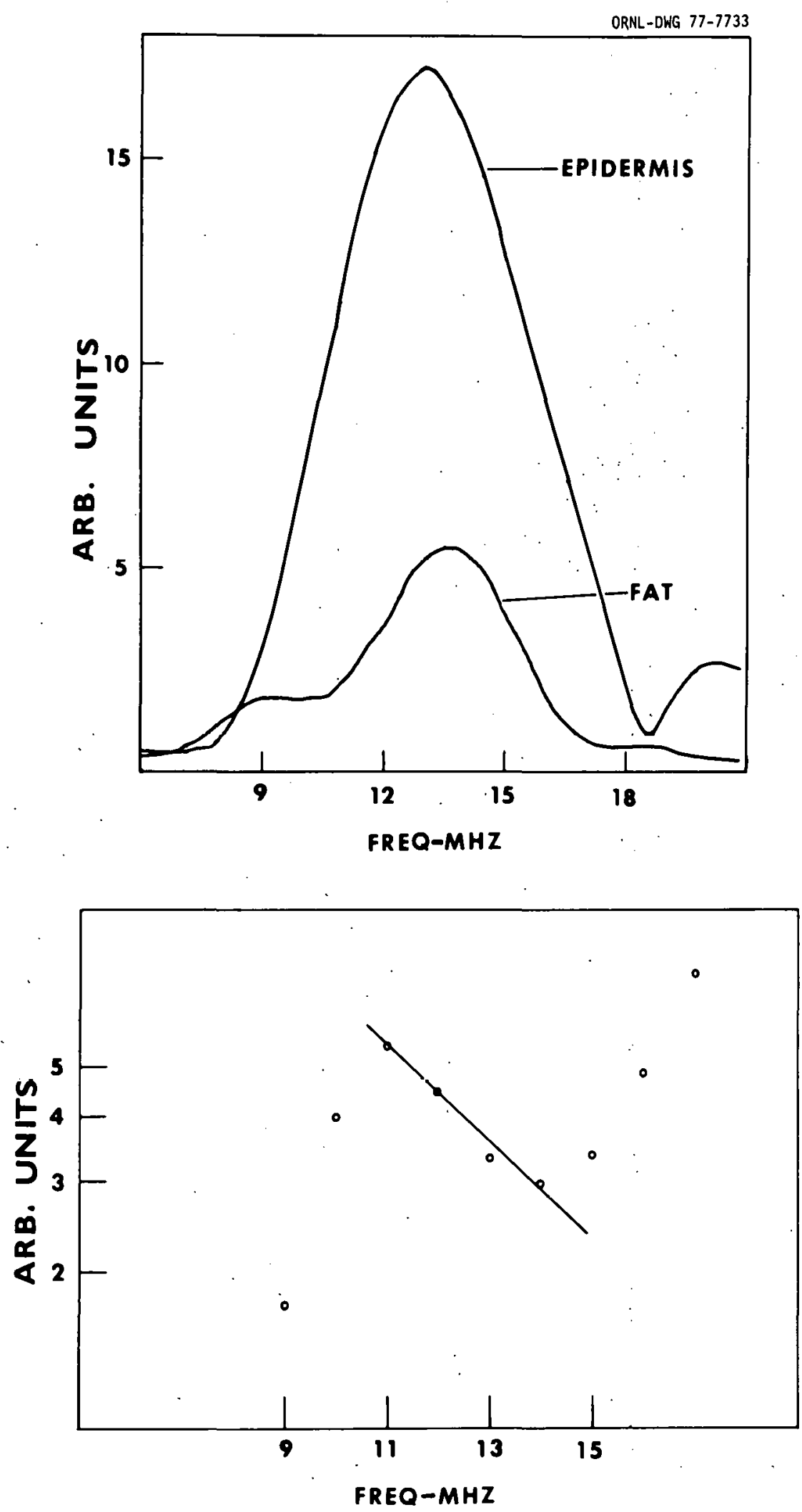

Figure 13. Frequency Spectrum -- Norma1 Tissue. 

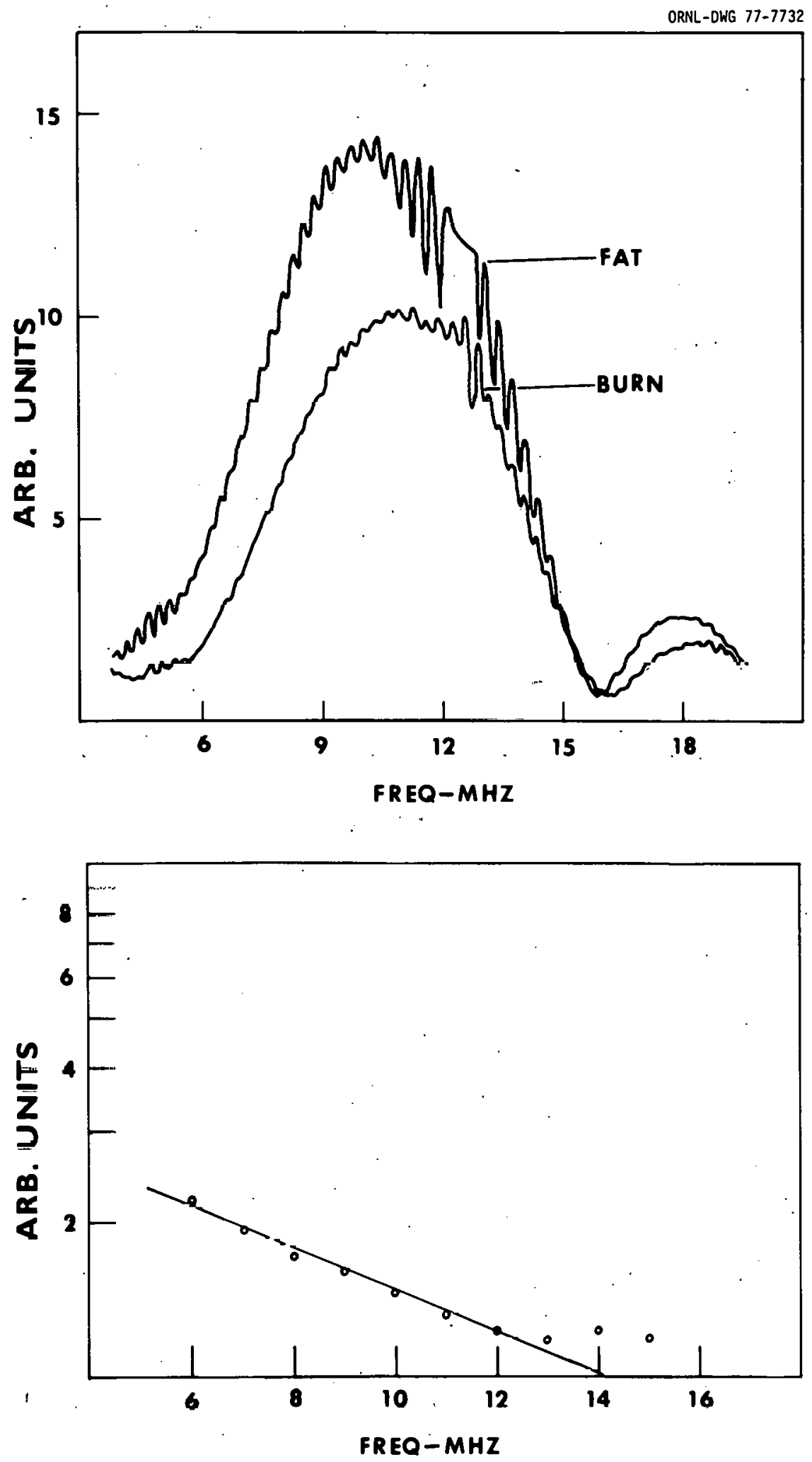

Figure 14. Frequency Spectrum -- Viable Tissue. 

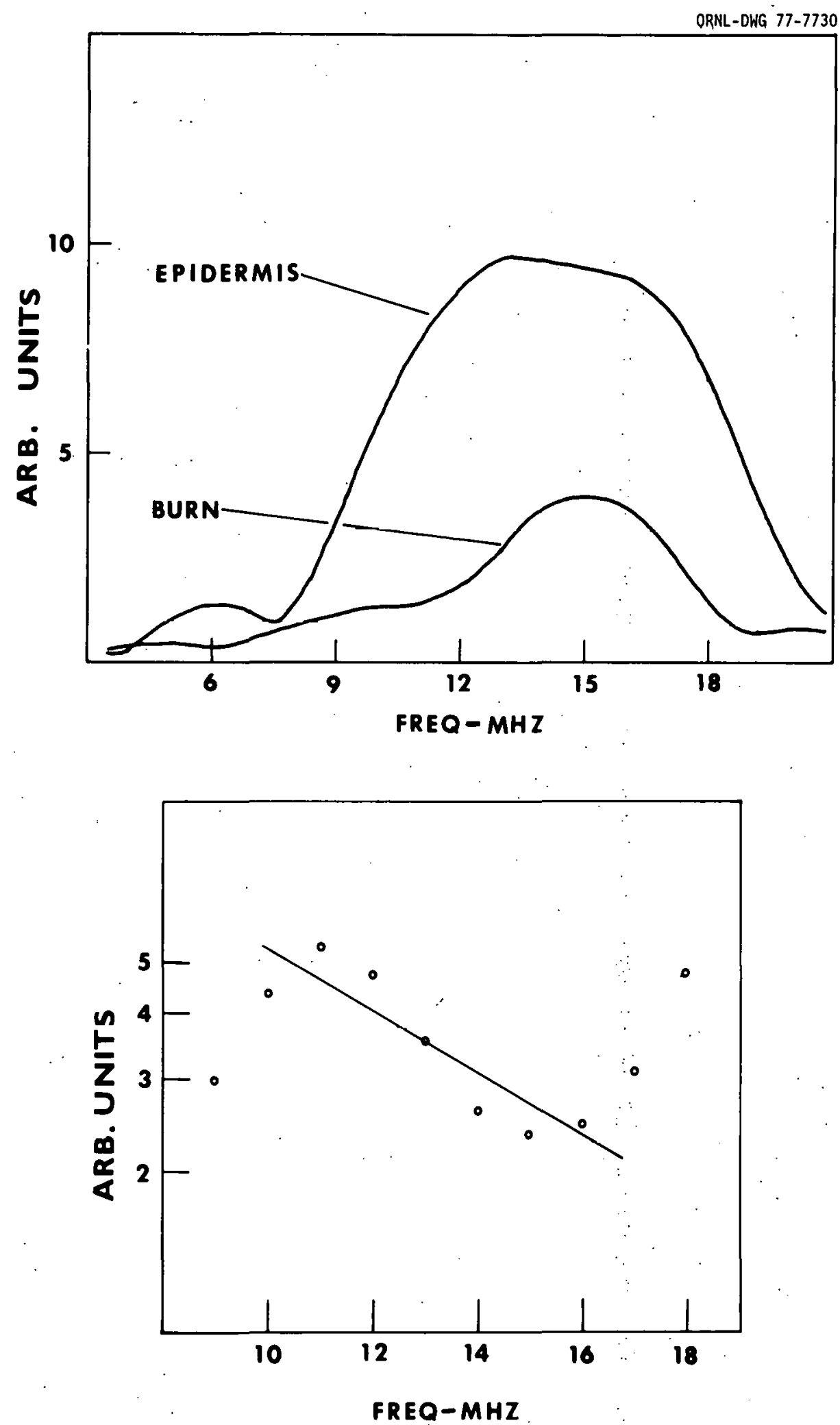

Figure 15. Frequency Spectruili -- Burned Tissue. 
were $0.30 \mathrm{~dB} / \mathrm{cm}$ and $0.59 \mathrm{~dB} / \mathrm{cm}$, respectively. These experimental values establish a significant difference in the attenuation of sound passing through samples of skin tissue exhibiting various conditions of viability. The spectra of the interfaces from viable tissue have the same general shape as those of normal skin layers, approximately Gaussian, and in both graphs the peak of the second reflection is shifted slightly to a higher frequency. With the viable tissue reflections however, the peaks are broadening, and the whole spectrum is shifted towards a lower frequency response. Where the first reflection from the normal surface centers about $13 \mathrm{MHz}$, the first reflection of the viable tissue centers around approximately $10 \mathrm{MHz}$. Also, the spectra of the viable tissue exhibit some modulation, particularly in the frequency range of 11 to $14 \mathrm{MHz}$. In contrast, the normal spectra are very smooth.

The spectra of the burned pig skin, again, are similar in shape to the other spectra. They are approximately Gaussian shaped, and the second reflection peak is shifted to a higher frequency than the first peak. The shape of the curve, however, is becoming more distorted and is broader than the viable tissue curves. Additionally, the whole spectrum for each interface has shifted to a higher frequency range, centered at approximately $14.5 \mathrm{MHz}$.

From these three figures, it can be concluded that the allerluation does differ significantly from burned to viable tissue layers. The spectral shape for each layer (burned to viable) changes, and the calculated attenuations are significantly different in going from the first layer to the deeper tissue below. Moreover it is interesting to note that the 
45

normal and viable spectra differ from each other significantly. The unburned skin layer below the burn is not left undamaged by thermal injury to the skin. The experimental data collection of the spectrum analysis measurements could be improved significantly if signal averaging were incorporated into the system. If several spectra (30-40) for each interface could be obtained and all averaged together, much of the uncertainty could be removed. For this to occur, a link to a minicomputer would be necessary. 


\section{CHAPTER IV \\ BURN DEPTH MEASUREMENTS}

A good model for performing research related to human cutaneous tissue, both normal and burned, appears to be that of the pig ( $K n 74$, Mo63, Wa73). While not identical, pig skin is more similar in structure to human skin than tissue from other available experimental animals. In both species, the epidermis is thick and has well differentiated under-sculpture. The dermis has a well defined papillary body and a large elastic tissue content, for both humans and pigs. In human skin, however, the dermis is well vascularized, while the pig dermis is less endowed with a blood supply. Considering the whole burn victim, the pig also appears to model the human wel1. At similar surface temperatures, there is little or no difference in the susceptibility of each epidermis to thermal injury. Fluid shifts within the burned and adjacent areas of pig skin closely resemble those of a human patient, and the erythrocytes (red blood cells) contain potassium which would be released during hemolysis (destruction of the cells), instead of sodfum as in other animals. Therefore, because of these findings, young (5-8 months) Yorkshire pigs became the experimental subjects for this research.

The scanning equipment for the experiments is shown in Figure 16. The echoencephaloscope is a standard medical ultrasonic unit manufactured by Hewlett-Packard (Model 7215B). The display is one-dimensional or A-mode, with the distance between reflections being the depth of the interface in the sample. The resolution of the system is approximately 
ECHOENCEPHALOSCOPE HP 7215B

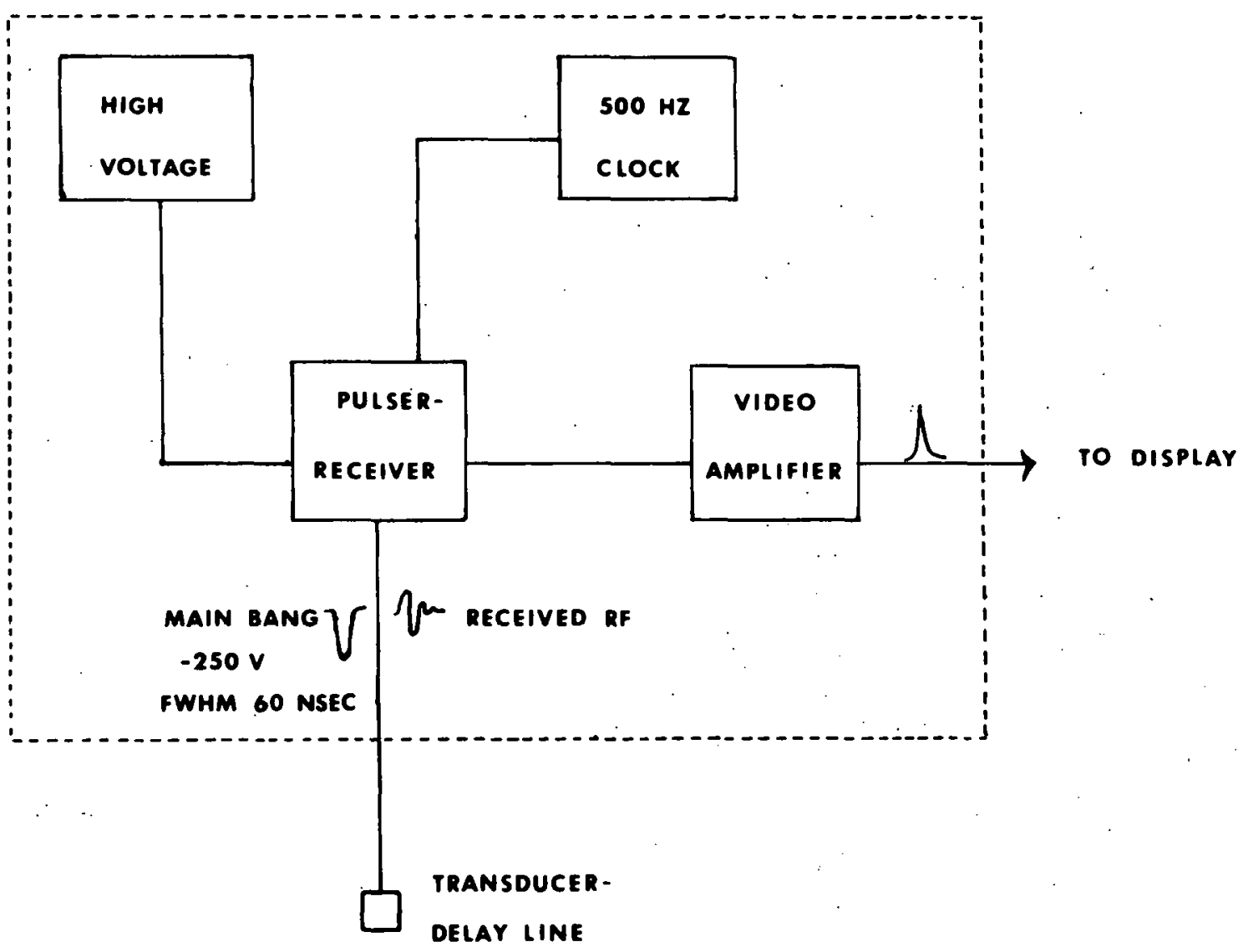

Figure 16. Electronics for Ultrasonic Scanning. 
$0.2 \mathrm{~mm}$, as illustrated in Figure 17. Displayed are the reflections from the surfaces of a lucite block. A measure of the full width at half maximum of the peaks (a method for determination of resolution) yields a value of $0.15 \mathrm{~mm}$. To obtain the high ultrasonic resolution needed for distinguishing millimeter and submillimeter distances in the skin, slight modifications were made in the electronics. A resistor in the time gain compensation circuitry was changed to modify the time ramp. This resulted in a greater gain slope in the region of interest which is approximately 1-10 mm. In the integrating circuit, the shaping capacitor was modified to create a faster decay time for shaping the pulse. Finally, because the depth of interest is only several millimeters, the horizontal display control was modified to $1 \mathrm{~mm} /$ div instead of $10 \mathrm{~mm} / \mathrm{div}$. A Hewlett-Packard camera fit onto the scope display, permitting the recording of the reflection pattern on Polaroid film.

The echoencephaloscope behaved much as the pulser-receiver in the spectrum analysis experiments. The unit both pulsed the transducer to produce the ultrasonic wave at a rate of 500 times/sec and received the reflected echo pattern from the transducer. The transducers. used for these experiments were the same as those described in Chapter III. To separate the "main-bang" from the reflected echo arriving from the first interface, the transducer was attached to the delay line. Initially, the bottom opening of the delay line was covered with a piece of common household plastic such as Saran. Wrap. The cylinder could then be filled with water or another good acoustic coupler. Contact to the skin was made with glycerin or a commercial acoustical coupling gel: This means of coupling had the potential of offering a smooth 


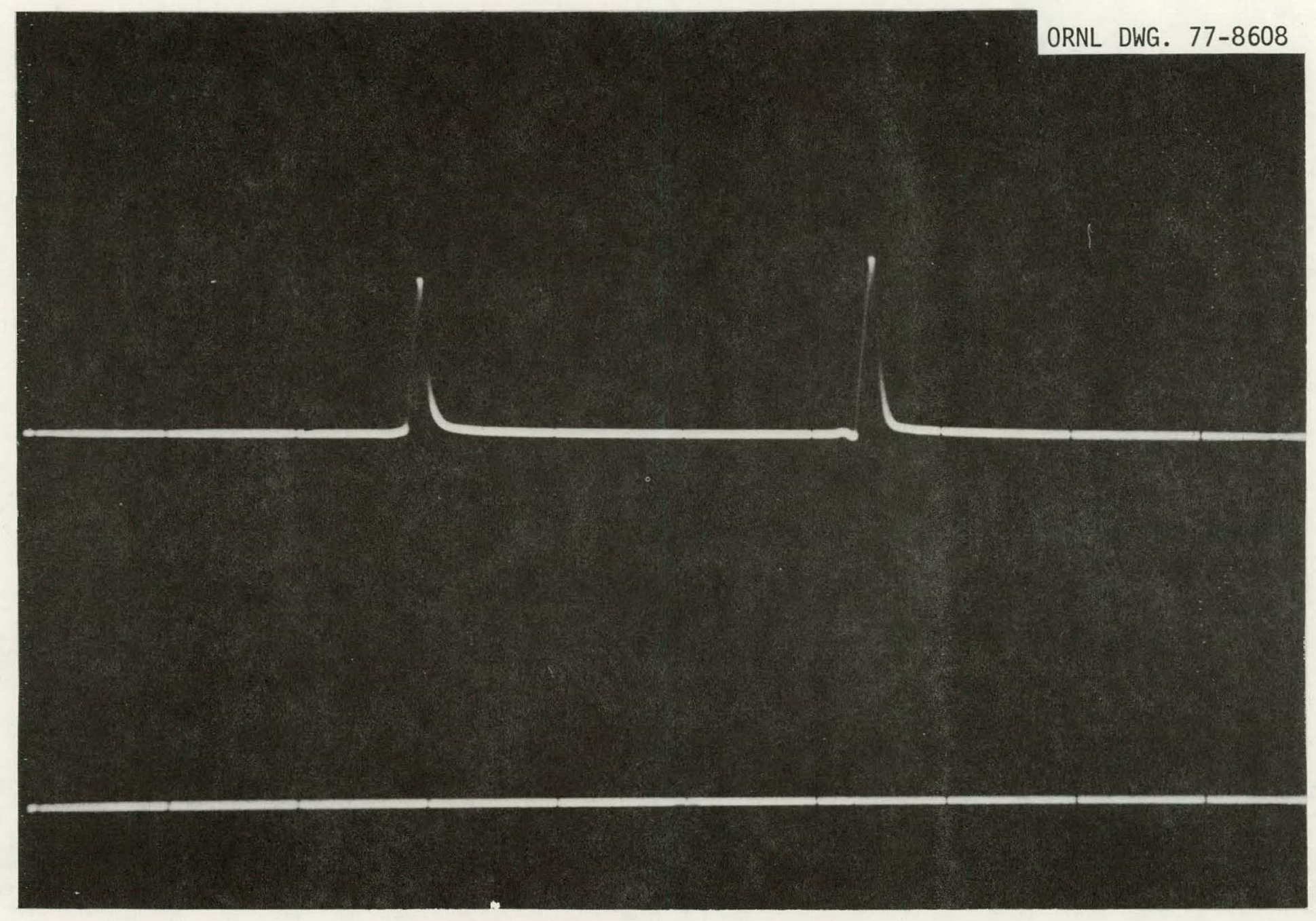

Figure 17. Resolution Determination. 
surface which could be drawn back and forth across the skin in a twodimensional scan. The disadvantage of the use of the plastic diaphragm on the delay line came when the echo patterns were measured for depth of burn or fat interface. Depending on the amount of gel used for coupling to the skin surface, the distance between the diaphragm and the epidermis changed; there was never an accurately known depth that could be subtracted from the distance measurements. Therefore, the diaphragm was permanently eliminated, and the commercial acoustic gel was used to fill the delay line. Figure 18 contrasts the two methods of coupling.

The two top scans are of a $20 \mathrm{sec}$ burn with and without the diaphragm, while the two bottom scans are of a $30 \mathrm{sec}$ burn. The diaphragm-no diaphragm difference for the two sets of data varies $\sim 0.1 \mathrm{~mm}$. This variance, as well as the diaphragm-no diaphragm difference, was not consistent throughout the data collection.

The burning iron initially used in the pig experiments was shaped in the form of a pointed elipse, approximately $\frac{1}{2}$ inch in minor axis, 1 inch in major axis, $\frac{1}{2}$ inch in depth and constructed of copper (Figure 19). Flat heating wire was wrapped around the copper and up the metal shaft connecting the iron to a cork hand grip. The wire then was covered with aluminum tape. A variable voltage source supplied the electrical energy for heating the iron, and a thermocouple placed manually on the outside of the iron recorded the temperature.

Several problems plagued this particular burning iron. There was no temperature feedback registering the actual burning temperature. 


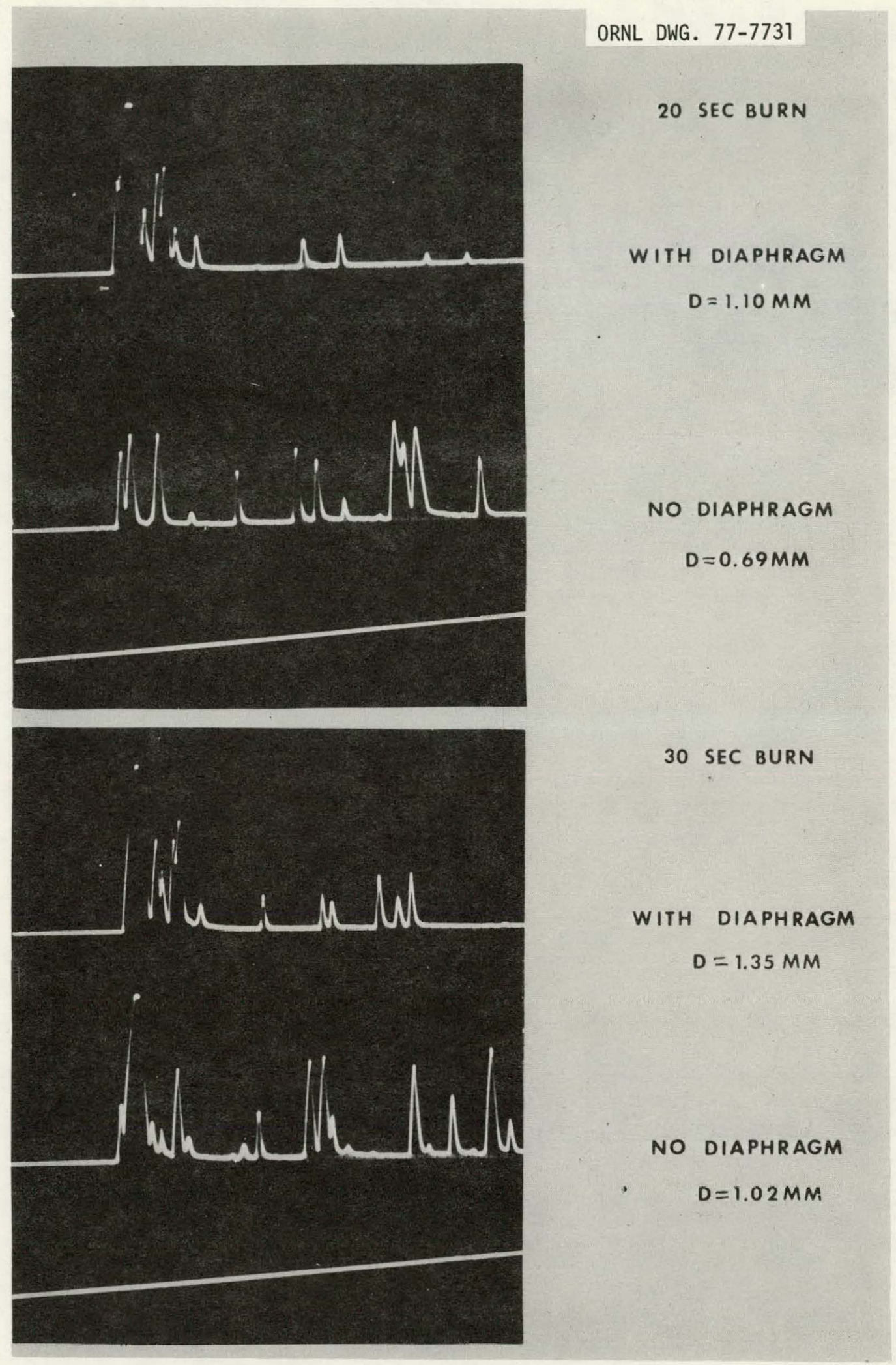

Figure 18. Comparison of Scans with and without Delay Line Diaphragm. 


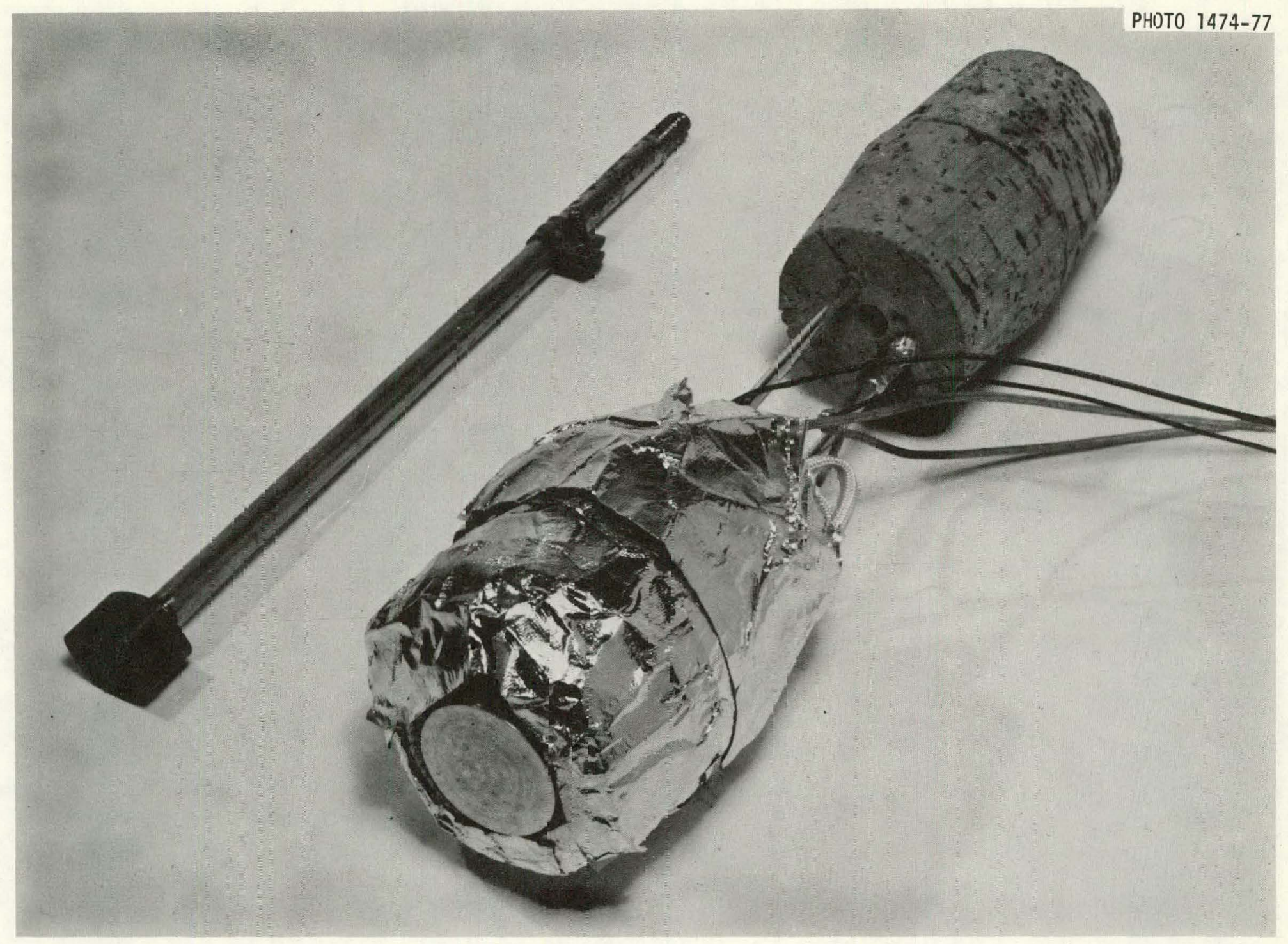

Figure 19. Burning Ircrs. 
The iron would begin at $100^{\circ} \mathrm{C}$, but immediately upon coming in contact with the skin would cool, sometimes $15^{\circ} \mathrm{C}$. This drop in temperature was the second important defect. A large heat sink was needed to supply the energy necessary to maintain the burning temperature.

In an attempt to construct an improved burning iron, a second design was tried (Figure 19). Aluminum was used due to its large heat capacity. To provide a large heat sink, the iron was 1 inch in diameter, and 3 inches long. Again, the flat wire was wrapped around the aluminum with aluminum tape on the outside. A small hole (1/16 inch diameter) bored down the center of the cylinder to within $1 / 8$ inch of the iron surface permitted a chromel-alumel wire to be implanted. A volt meter connected to the thermocouple wires permitted direct reading of the temperature which then could be used to regulate and manually maintain the temperature. In this way the burning temperature was known throughout the burn and could be maintained at $100^{\circ} \mathrm{C}$.

Five experiments, each using a different pig, were performed over the course of this research. Experiments 1, 2, and 4 were performed for the purpose of measuring burn depth with the ultrasonic scanning technique and making comparisons with slides of histological sections taken from the burns. Removal of the plugs for histology occurred at various days postburn, depending on the experiment. The day of the burning was day 1 . The burns in experiments 3 and 5 were to be used for density and spectrum analysis measurements, although the burns in experiment 3 were scanned ultrasonically for a limited period, but without histological sections taken for comparison. 
Preparations for each experiment were basically identical. The pig was kept in a sty in an animal barn. Several days were allowed to elapse after his initial placement in the barn so he might become familiar with his new surroundings. This time also was used to acquaint the pig with the investigators. Both procedures made dealing with the pig considerably easier during the experiment itself.

On the first day of each experiment, the burning would take place. The iron was turned on and allowed to come to equilibrium in the barn several hours prior to its use. Before burning, the veterinarian would inject the pig with an anesthetic, usually a drug containing sodium secothal and mephuisin, to render him unconscious. This was not always an easy task. The injection was made through an ear vein; which usually happened to be sensitive to needle pricks. In addition, pigs are susceptible to respiratory distress under the influence of an anesthetic. Once unconscious, the burns were made on the dorsal surface of the animal in a line parallel to the spine. The wounds were kept high on the back to prevent the pig from scratching them on the walls or posts of the sty. The burning temperatures were nominally $100^{\circ} \mathrm{C}$, but, as mentioned previously, the second iron proved to be better able to maintain the specified temperature. During any one burn the temperature varied $\pm 3^{\circ} \mathrm{C}$ maximum. The burning times and number of burns made varied depending on the experiment.

Experiments 1 and 2 were performed to obtain burn depth data using the ultrasonic scanner and to correlate the scans to histological sections of the burns. Further, they provided the means to test the new delay line and diaphragm. Nine burns were made during the first two experiments. Three $10 \mathrm{sec}$, three $20 \mathrm{sec}$, and three $30 \mathrm{sec}$ burns comprised experiment 1, with 
sections from each burning time being removed at day 1, day 3, and day 6 . Three each of $30 \mathrm{sec}, 45 \mathrm{sec}$, and $60 \mathrm{sec}$ burns were given in experiment 2. The plugs for the histology were removed at day 1 , day 4 , and day 12 . This experiment permitted the investigators to observe the burns for an extended period. Figures 20 and 21 and Table II are examples of the typical observed data. From Table II, it is clear that the ultrasonically measured depths accurately define wound depth as measured in the histology slides. Figure 20 is the ultrasonic comparison of the depth of burn for different burning times. The scans presented are taken without the diaphragm on the delay line. As would be expected, the depths increase as the burning time increases. Figure 21 is a comparison of one $30 \mathrm{sec}$ burn as it progresses through the experiment from day 3 to day 12 . The depth of damage remains relatively stable for the first few days postburn but then begins to increase. This deepening of the wound necrosis could be due to infection. As was stated earlier, it was concluded from these experiments that the diaphragm would not allow accurate depth measurements (see Figure 18).

With experiment 3 , the new burning iron was implemented. It was obvious during the burning that the burns were going to be more severe. Therefore, the times were limited to $20 \mathrm{sec}, 30 \mathrm{sec}$, and $45 \mathrm{sec}$. Two burns were given for each burning time. Ultrasonic scan data were collected on day 1 and day 4 , but, the purpose of this experiment was to investigate the densities and attenuations of the normal, viable, and burned tissues. Thus, no skin plugs for histology sections were taken. On day 4 the plugs were removed. One plug from each burning time was 
Table II. Burn Data -- Slide Depth Versus

Film Depth

\begin{tabular}{lll} 
Burn & S1ide Depth & Film Vepth \\
\hline $30 \mathrm{sec}$ & $0.95 \pm 0.20$ & $0.95 \pm 0.02$ \\
$45 \mathrm{sec}$ & $1.69 \pm 0.19$ & $0.73 \pm 0.02$ \\
$60 \mathrm{sec}$ & $2.25 \pm 0.07$ & $2.26 \pm 0.08$
\end{tabular}




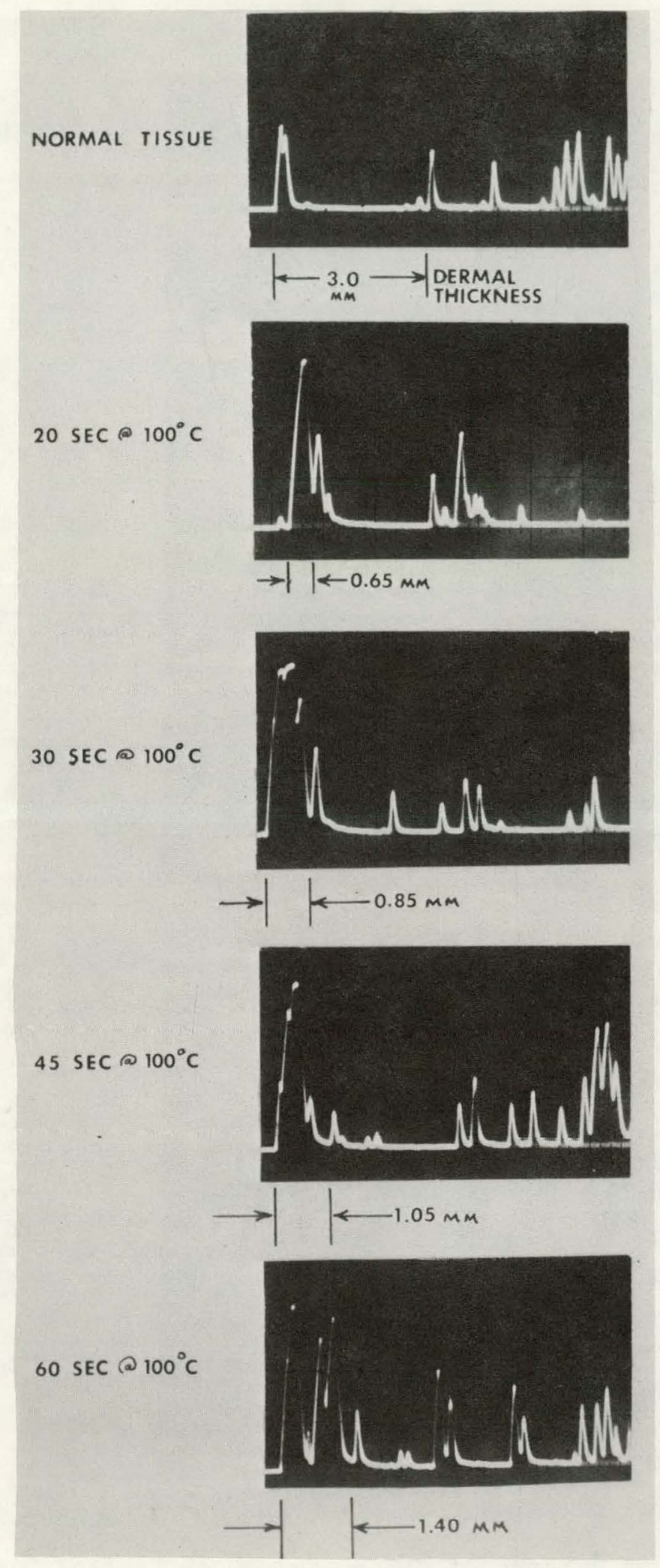

Figure 20. Burn Depth for Several Burns. 


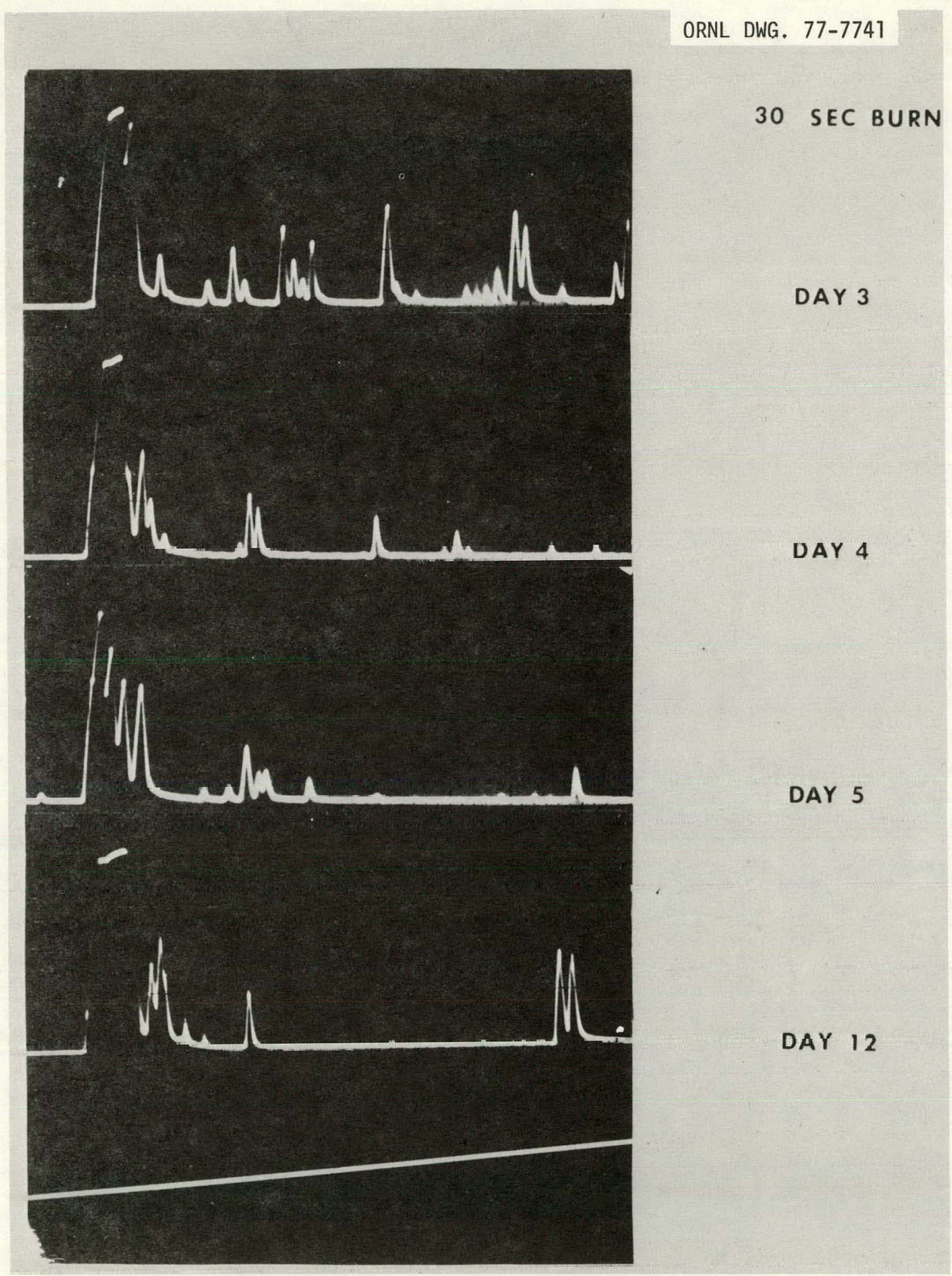

Figure 21. Scans of $30 \mathrm{sec}$ Burn Over Several Days. 
wrapped in plastic and placed in liquid nitrogen. The quick freezing preserved the tissue until it could be analyzed with the spectrum analyzer in the laboratory. The rest of the plugs were utilized immediately for density measurements using the displacement method described in Chapter III.

Because of the severity of the burns induced by the new iron, another experiment for determining depth of burn was performed. In experiment 4, eight burns were made along the pig's back--two burns for each category of $20 \mathrm{sec}, 30 \mathrm{sec}, 45 \mathrm{sec}$, and $60 \mathrm{sec}$ times. Excision of the plugs for histology occurred at day 1 and day 6 . Figures 22-24 and Table III are representative of the ultrasonic data collected from experiments 3 and 4 .

Figure 22 is a comparison of different burns on day 4 from experiment 3. Day 1 from experiment 4 is shown in Figure 23. With increased burning time, the burn depth increases. The $60 \mathrm{sec}$ burn in Figure 23 is an excellent illustration of necrotic tissue. The tissue composition is very rough, causing many ultrasonic reflections; unlike the normal tissue, which is relatively homogeneous, thereby causing few reflections. The histological appearance of the burn wound is shown in Figure 25. Figure 24 is a composite of a $60 \mathrm{sec}$ burn through several days. The burn depth increases throughout. The fat interface is at its maximum on day 3 and then begins to decrease. The appearance of a maximum fat distance is probably due to edema. In humans, edema is maximal also at approximately 48 hours (Ar73). Table III relates histology slide depth to ultrasonic depth. Again, the correlations are good.

The purpose of burning the pig in experiment 5 was to collect more tissue samples for density measurements and spectrum analysis. Seven burns were induced, six $45 \mathrm{sec}$ burns, and one $60 \mathrm{sec}$ burn. Three of the $45 \mathrm{sec}$ 


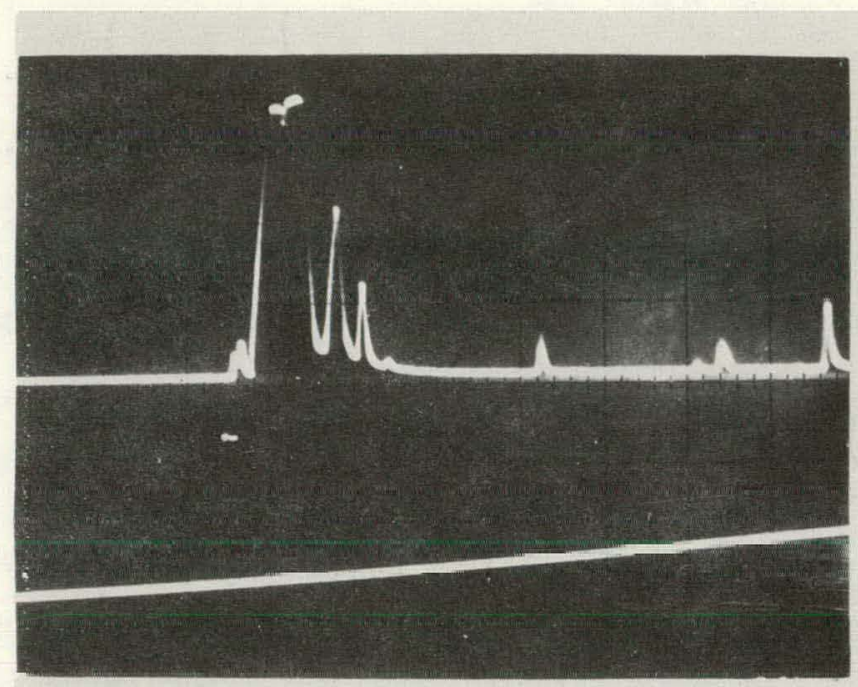

ORNL DWG. $77-7740$

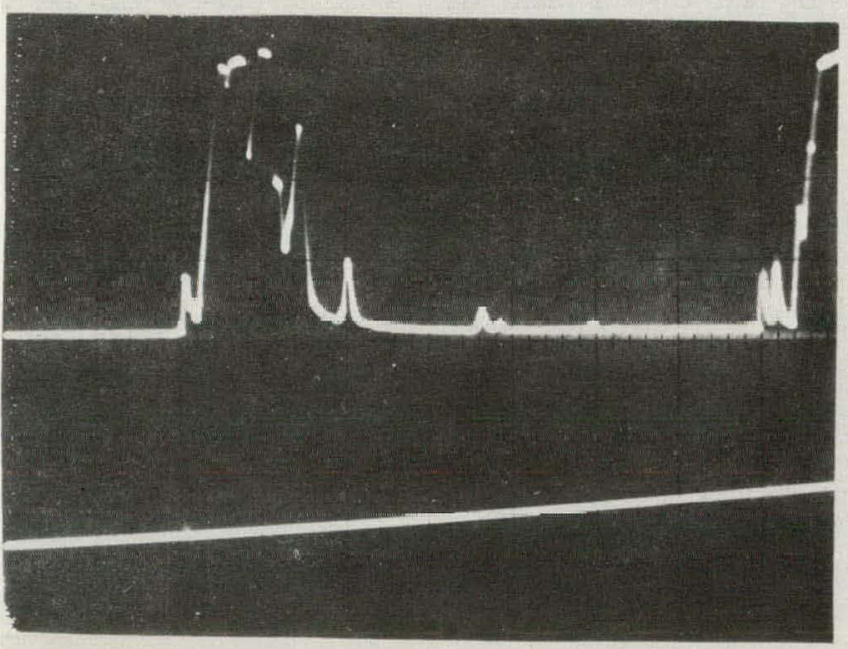

20 SEC BURN

$D=0.88 \mathrm{MM}$

30 SEC BURN

$D=1.09 \mathrm{MM}$

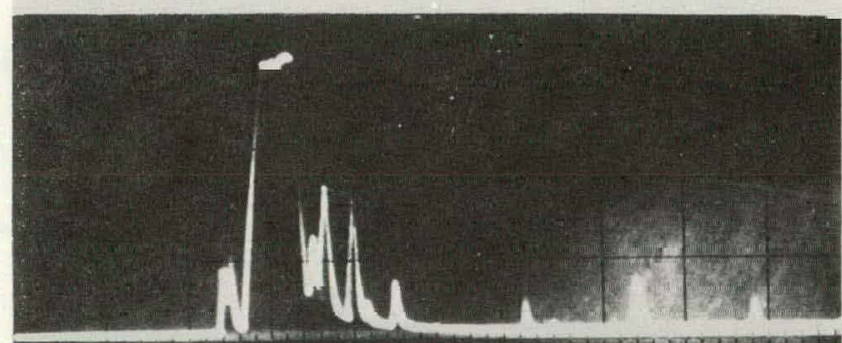

45 SEC BURN

$D=1.83 \mathrm{MM}$

Figure 22. Burn Depth for Several Burns. 


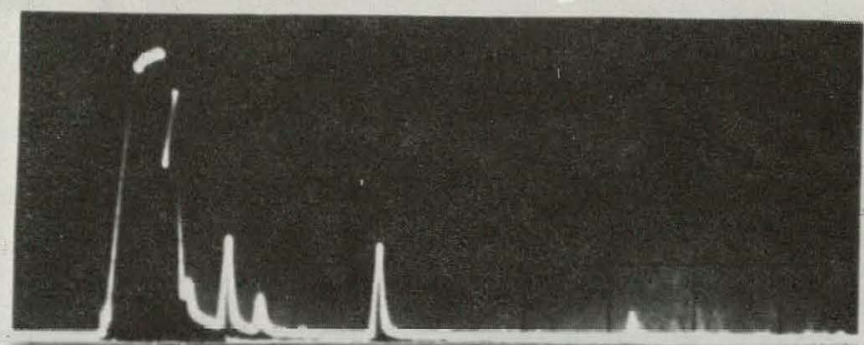

ORNL DWG. 77-7742

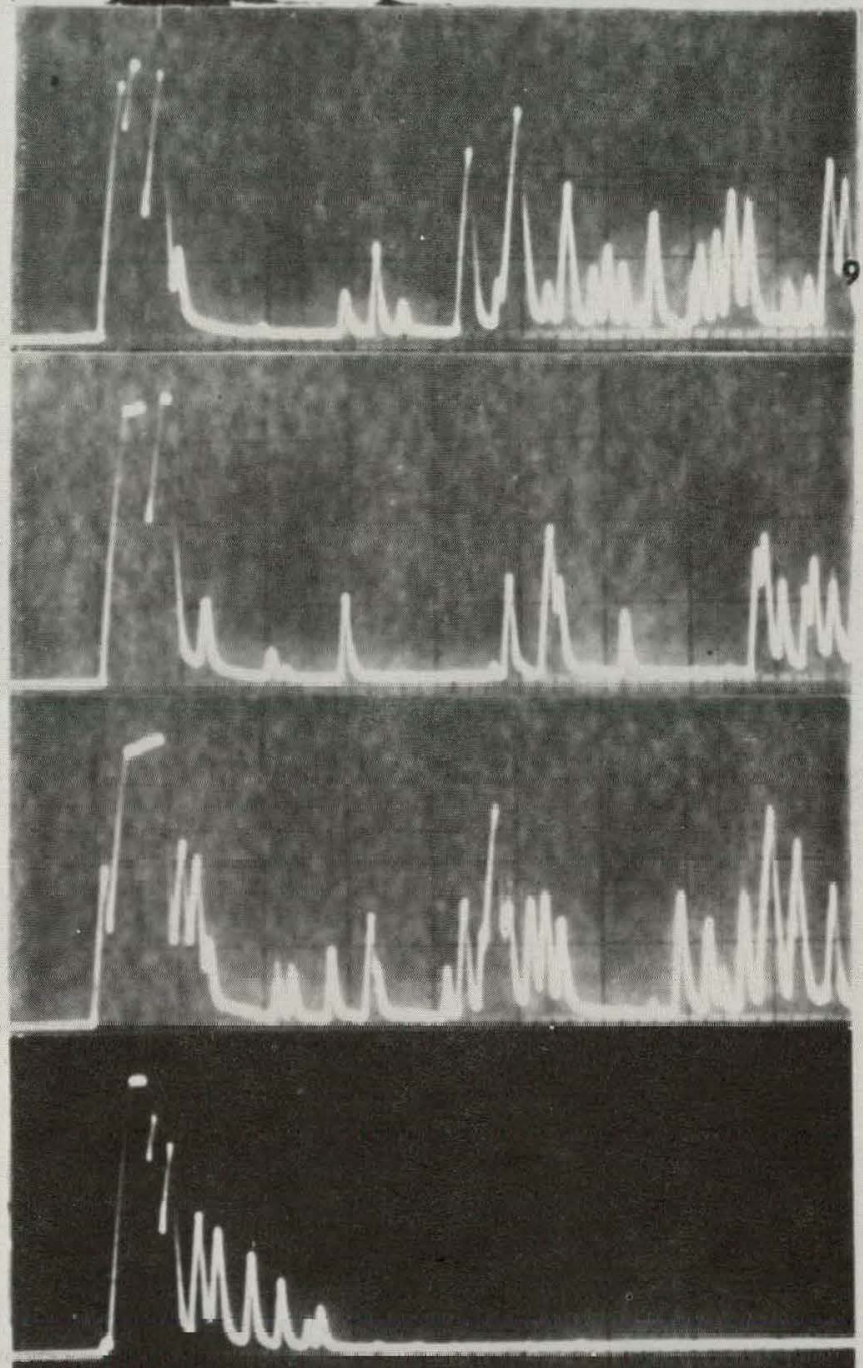

NORMAL

20 SEC BURN

$\mathrm{D}=0.87 \mathrm{MM}$

30 SEC BURN

$D=1.12 \mathrm{MM}$

45 SEC BURN

$D=2.81 \mathrm{MM}$

GO SEC BURN

$\mathrm{D}=2.40 \mathrm{MM}$

Figure 23. Burn Depth for Several Burns. 


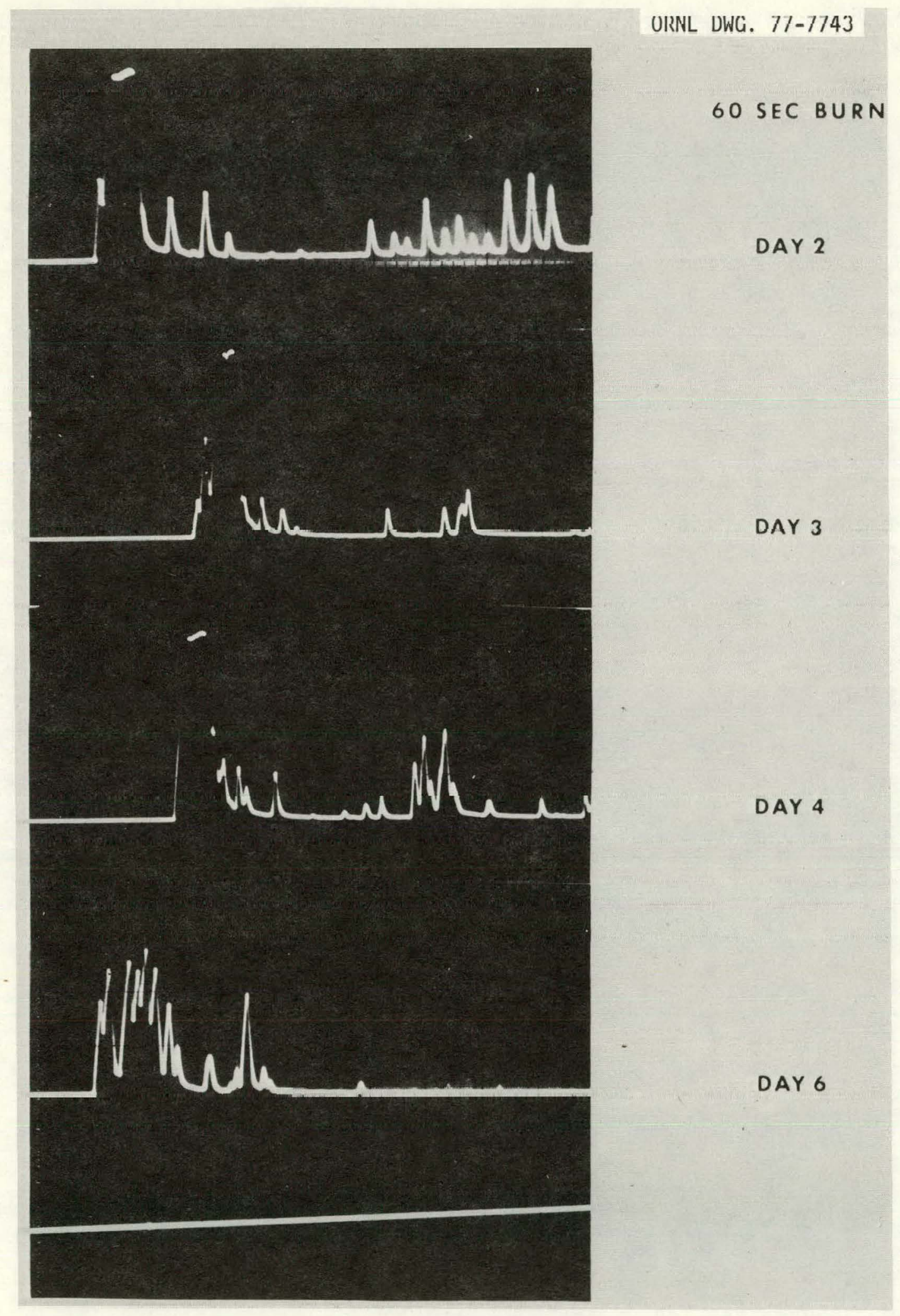

Figure 24. Scans of $60 \mathrm{sec}$ Burn Over Several Days. 
Table III. Burn Data -- S1ide Depth Versus Film Depth

\begin{tabular}{lll} 
Burn & S1ide Depth & Film Depth \\
\hline $20 \mathrm{sec}$ & $0.76 \pm 0.11$ & $0.89 \pm 0.04$ \\
& $0.83 \pm 0.04$ & $0.87 \pm 0.03$ \\
$30 \mathrm{sec}$ & $3.14 \pm 0.26$ & $3.10 \pm 0.02$ \\
& $1.07 \pm 0.08$ & $1.12 \pm 0.01$ \\
$45 \mathrm{sec}$ & unmeasurable & $2.81 \pm 0.04$ \\
$60 \mathrm{sec}$ & $1.81 \pm 0.15$ & $1.87 \pm 0.09$ \\
& unmeasurable & $2.40 \pm 0.05$
\end{tabular}




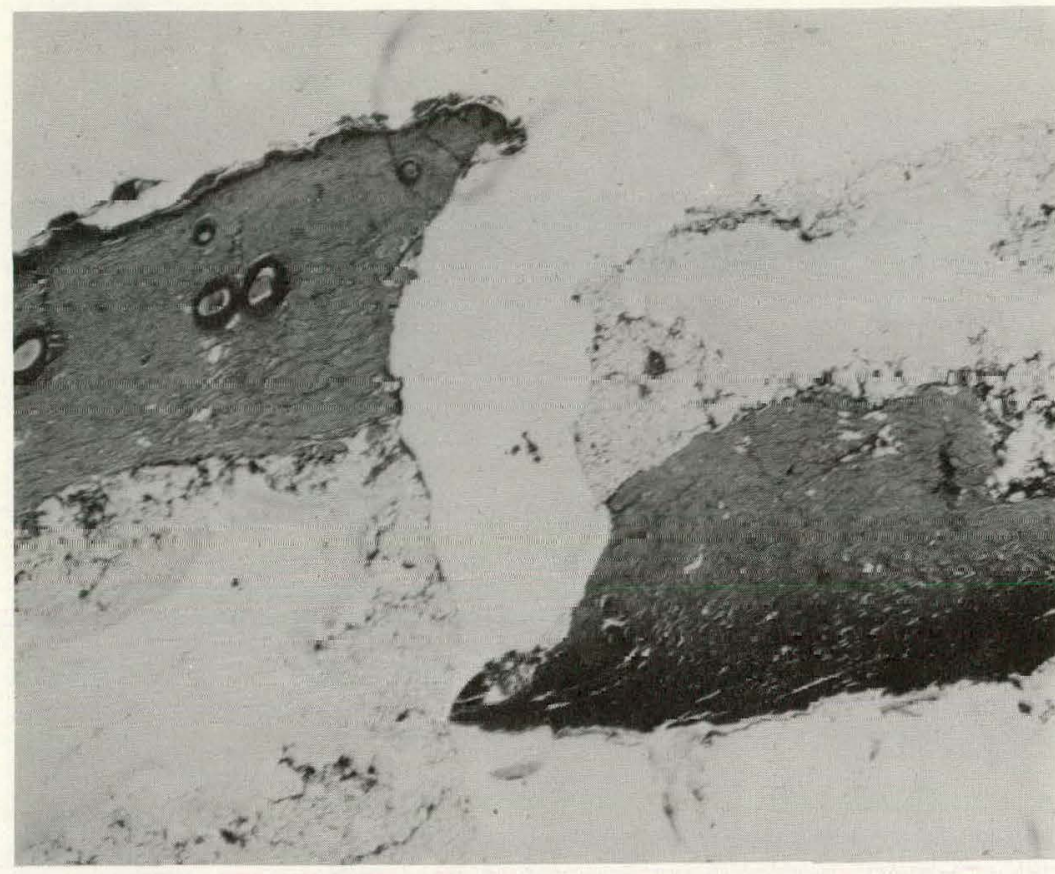

Normal Tissue

Burned Tissue

$(4 x)$

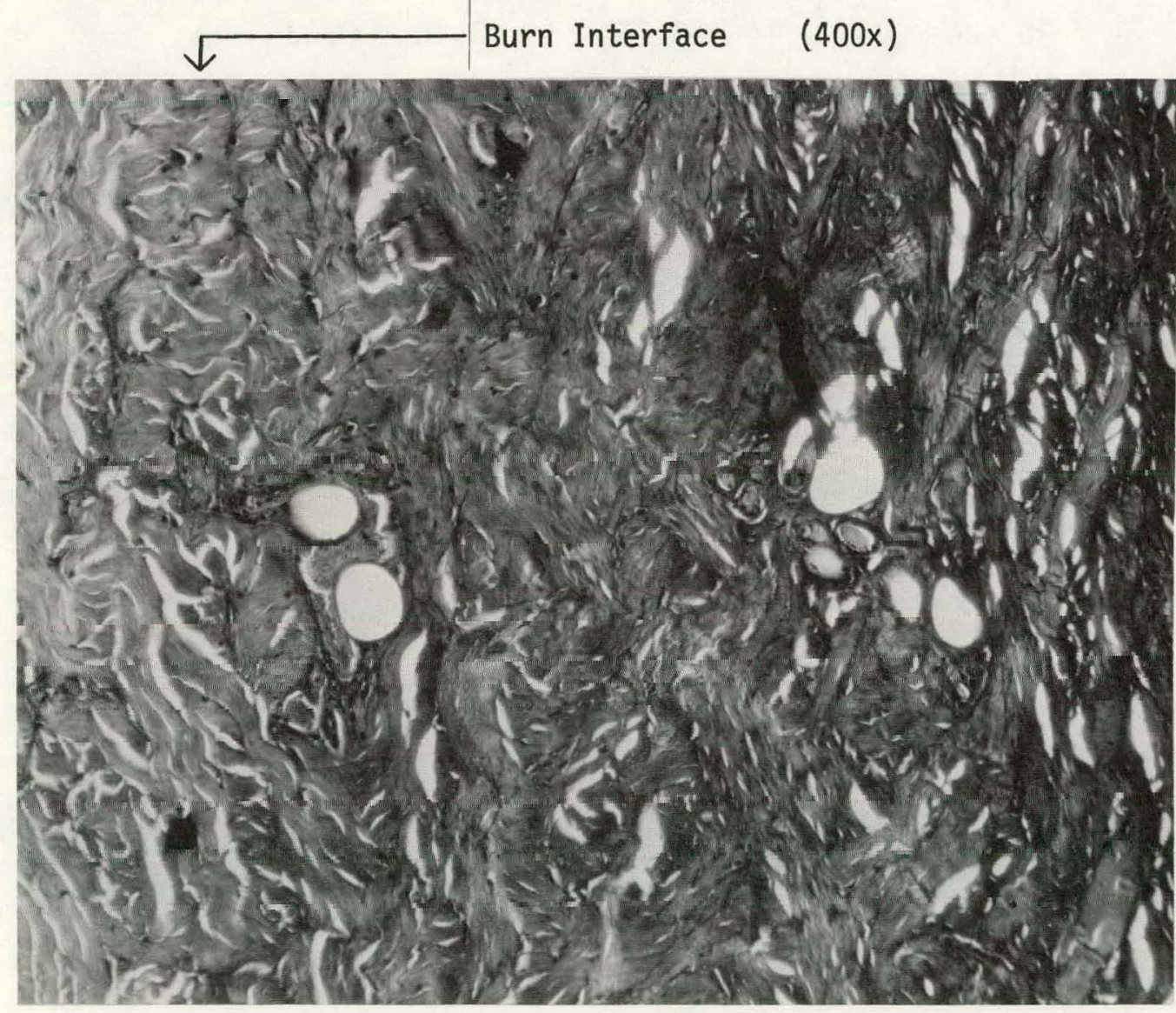

Figure 25. Histology Slide of Normal and Burned Porcine Skin. 
burns were used for the spectrum analyses, and the rest provided density information with the copper sulfate method described in Chapter III. No ultrasonic scans were made.

In reviewing generally the data collected from all of the pig experiments on burn depth, several trends can be discussed. The burn interface is definable immediately postburn on day 1 . With the days following, the burn depth increases, and this also is observable. The fat interface begins to deepen as a function of time almost immediately postburn until a maximum is reached, about day 3 or 4 . After this point, the distance to the fat decreases somewhat, but then remains relatively constant. The important conclusion is that the depth of a burn can be identified using ultrasonic scanning.

Human burn data were not available for this research because of the extended time necessary for a human use committee's approval of the research protocol. However, some limited work was performed on normal skin to illustrate the applicability of the technique to humans. Figure 26 presents ultrasonic scans taken from the dorsal side of the hand and the ventral side of the wrist. These scans establish that the structures underlying the skin, as well as the skin layers, can be identified. Figure 27 is an ultrasonic view of a human chest. View $A$ is an expanded view with $1 \mathrm{~mm} /$ div. The epidermis and fat interfaces are readily observable, and at approximately 11.5 div beyond the epidermis, the reflections from the lung region begin to appear. View B gives a more graphic display of the reflections caused by the lungs and particularly, the air within the lungs. 


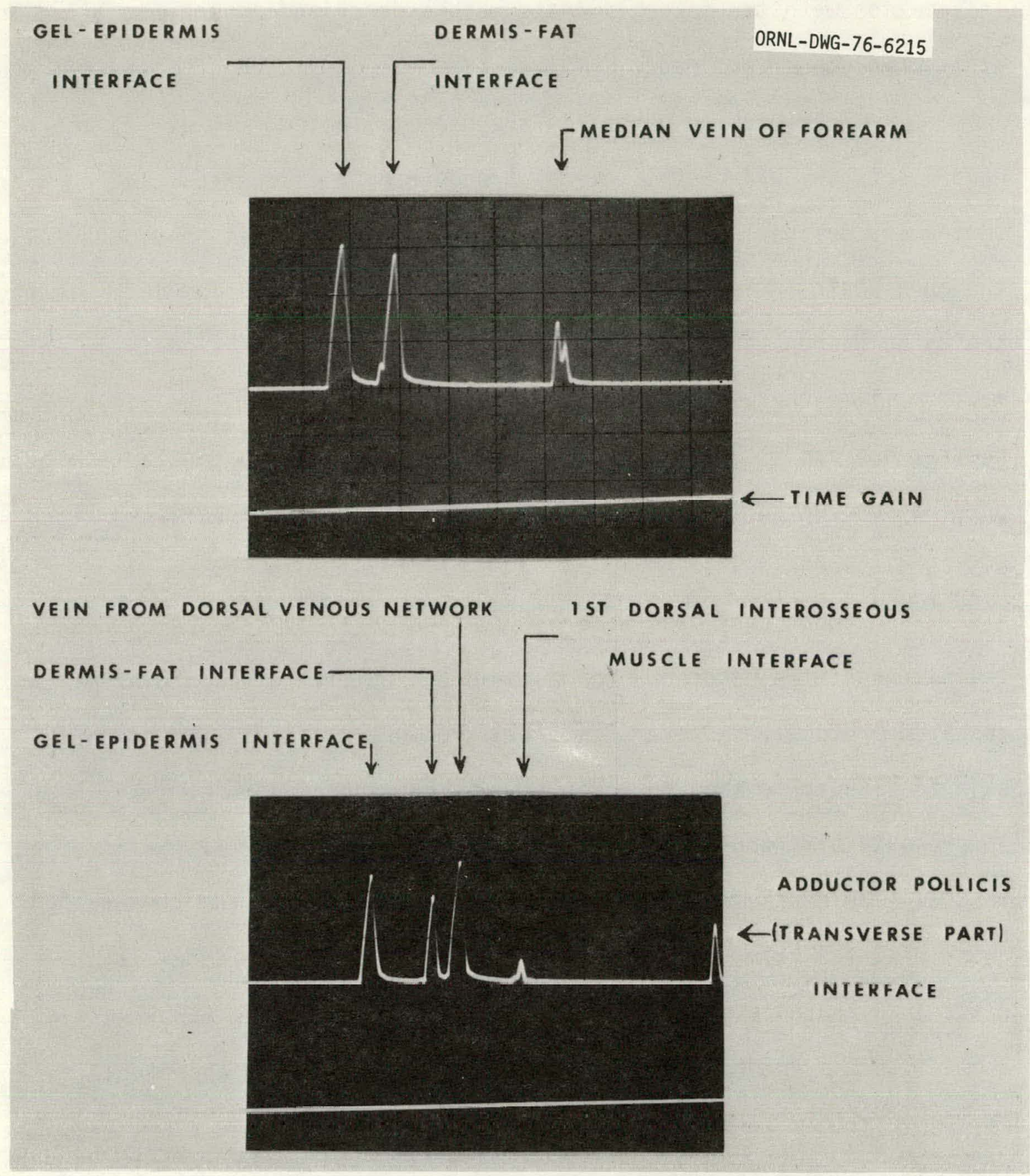

Figure 26. U1trasonic Scans of Wrist (Top Scan) and Hand (Bottom Scan). 


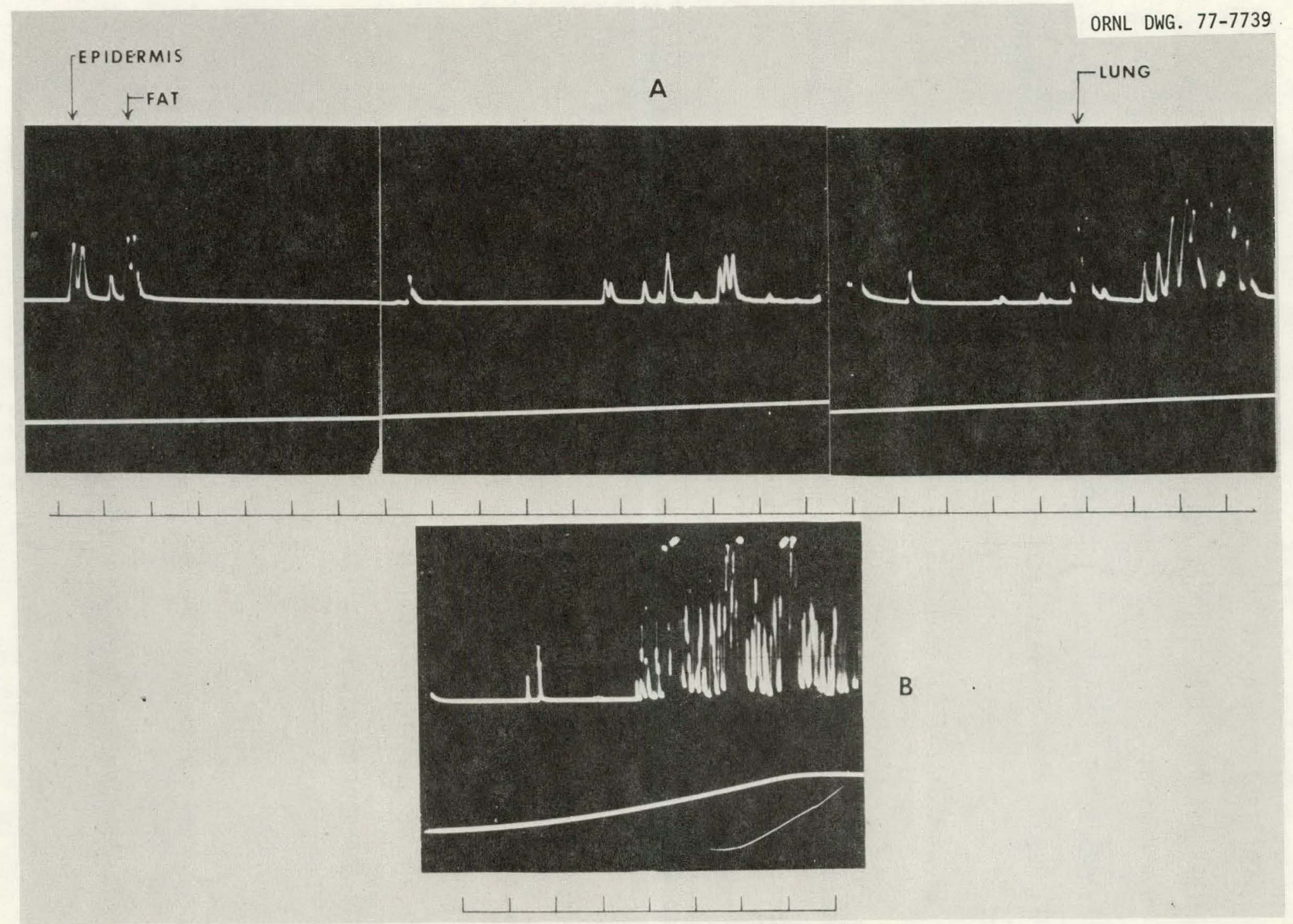

Figure 27. Ultrasonic Scan of Human Chest. a. $1 \mathrm{~mm} /$ div. b. $5 \mathrm{~mm} / \mathrm{div}$. 
A-mode, or one dimensional, scanning is limited in its ability to impart information to the user. B-scanning, or two dimensional scanning, is the more desirable approach to viewing the burn profile, since a whole burned area can be studied rather than iust one point at a time. Figure 28 displays a two dimensional rectilinear scanner constructed for this research, but, due to time limitations, was not fully developed. The transducer on the end of the horizontal rod is in contact with the patient. By turning the screw controlling the movement of the top plate in the direction parallel to the rod, the transducer can be used manually to scan the patient. To obtain the horizontal display of this movement on the scope, a linear potentiometer is attached to the top plate and sends electrical signals to the scope corresponding to the position of the transducer. The vertical display on the scope is obtained by electrically manipulating the reflection pattern from the echoencephaloscope. Each echo becomes a dot vertically positioned on the scope by synchronizing the echo pulse with a ramp. Fast electronics necessary to resolve echo pulses separated by $<0.5 \mu \mathrm{sec}$ have now been implemented but because of time limitations, two-dimensinnal data are not available for this thesis. These experiments will be the basis for another study. 


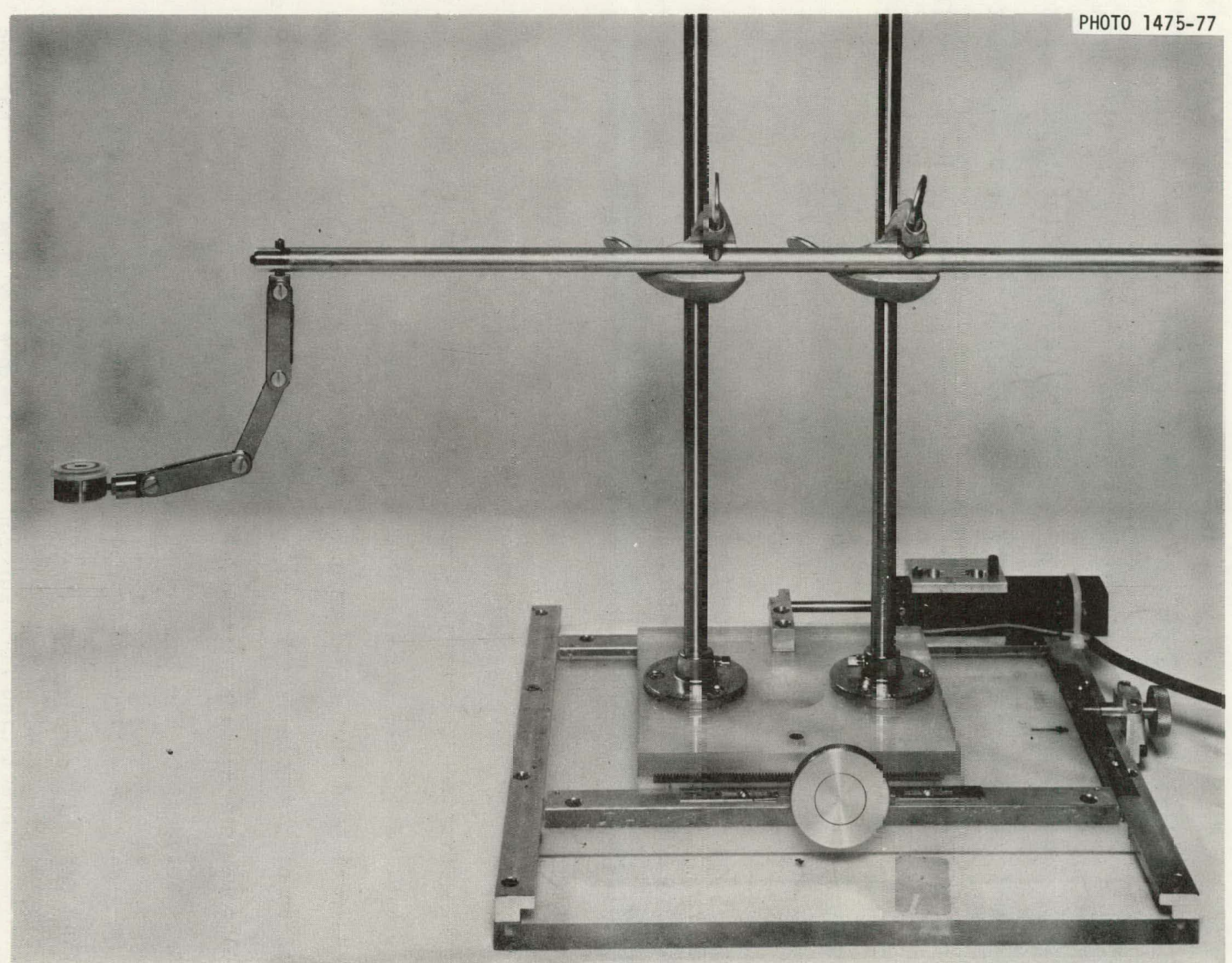

Figure 28. Two-Dimensioral Scanner. 


\section{CHAPTER V \\ CONCLUSIONS AND DISCUSSION}

U1trasonic scanning of a burn wound can be a very effective tool in aiding the physician in the prognosis and treatment of the burn victim. Because the depth of the burn can be readily established, second and third degree burns can be separated early, and the appropriate treatment begun for both, thus minimizing wound morbidity and patient mortality. However, several problems have yet to be solved. As mentioned in Chapter IV, two or three dimensional scanning is the ultimate goal for presenting the burn profile to the physician. The two-dimensional scanner described in that chapter is rectilinear and is a beginning for picturing the burn region. But, it has the limitation of being unwieldy in dealing with curves and edges of the patient. Commercially available ultrasonic units used in other medical fields utilize a sine-cosine potentiometer to overcome this problem of angles. Such a unit would be of great advantage to burn research. Computerization of the data collection would also facilitate the use of this system by the physician, as a three dimensional grid plot could be obtained for use within surgery while the excision of the burn is taking place (Figure 29). The computer could aid also in performing many of the calculations needed early in treatment, such as determining the total body surface area (BSA), fluid replacement regimen, etc. A disc-based computer system has just recently been installed for this purpose at ORNL.

A practicing burn surgeon (St76) expressed the view that one source of major concern in dealing with a burn victim is the proper healing 


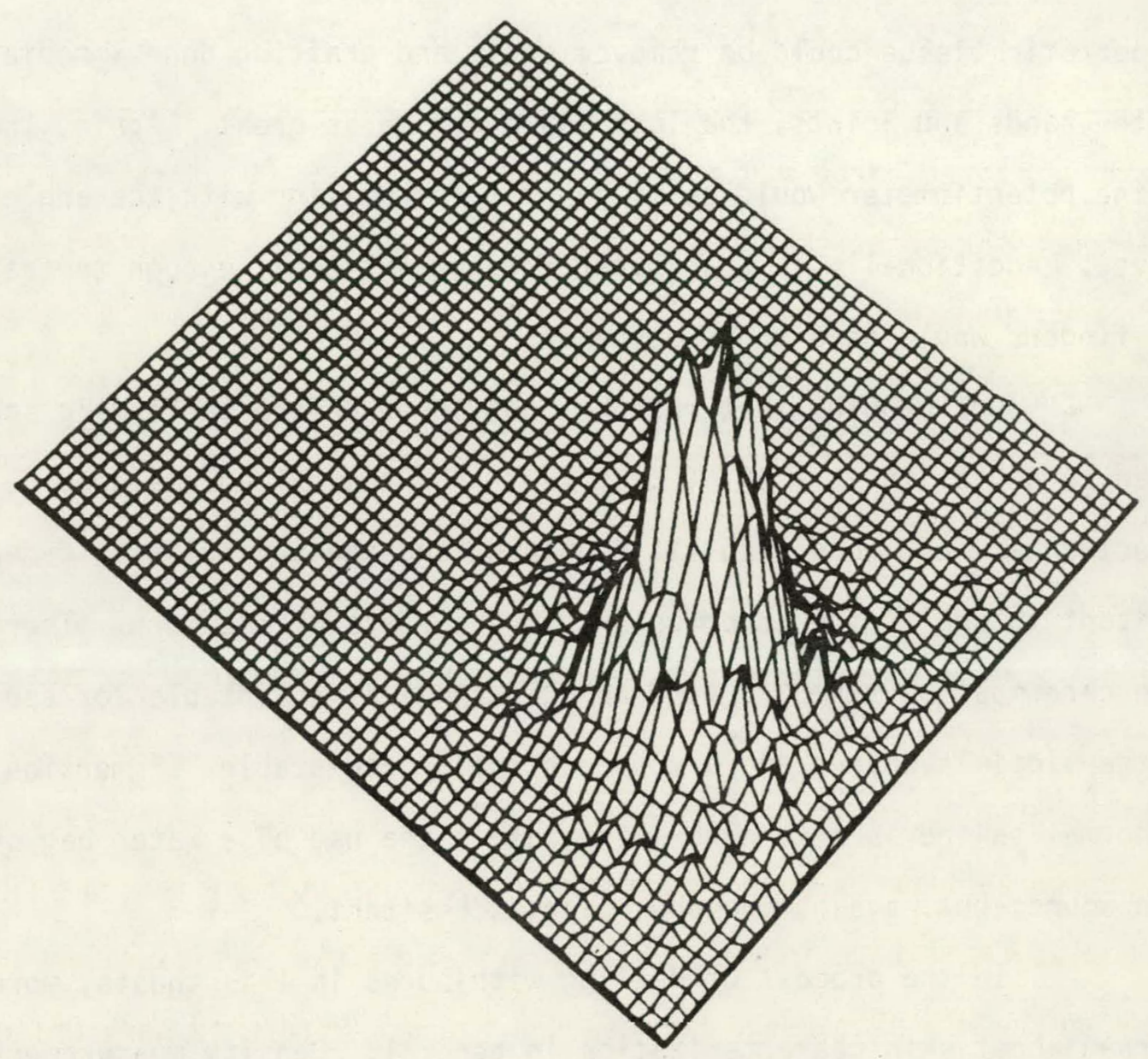

Figure 29. Computer Drawn Three-Dimensional Plot. 
of joints and the hands. With the formation of contracting scar tissue, joints are often made unmoveable, and painful plastic surgery must be performed with extensive physical therapy afterwards. The hands can quickly lose their function or must be amputated because of infection. Therefore, if necrotic tissue could be removed early and grafting done immediately on the hands and joints, the loss would not be as great. Again, the sinecosine potentiometer would be of benefit for dealing with the angles involved. Additionally, a transducer arrangement small enough to travel the fingers would have to be designed.

One problem that must be considered before performing scans on human burn victims is that of coupling. The topical agents used to prevent infection are not good acoustic couplers, and the physician is understandably hesitant to apply other chemicals to the surface of the burn. Therefore, some care must be taken to find an agent that is acceptable for application to the victim's wounds and also acoustically acceptable. Immersion in water or normal saline is a consideration, as is the use of a water bag over the burn wound; but, again, the physician is hesitant.

In the process of dealing with burns in this thesis, more has been learned about skin characterization in general. Density measurements showed that the burned, viable and normal tissues were not significantly different in their densities at approximately day 3 or day 4 postburn. Edema may be the cause of this unchanged condition. Fourier spectrum analysis established that a change occurs in the attenuation of $u 1$ trasound through the various tissue samples though, thus producing a change in the impedances of the various layers. This impedance mismatch leads to the reflection at the interface between the burned and viable tissue layers. 
Several improvements in the spectrum analysis data collection would be of great benefit in obtaining more and better data on attenuation. Reproducibility was not always possible as is shown in Figure 30 in comparison to Figure 15 in Chapter III. Both graphs were taken with the same tissue sample, only Figure 30 was obtained some time after Figure 15. The difference may be due to the interaction of the acoustic gel with the tissue itself. Also, as stated earlier, the decision of what spectra to record as data is a very subjective procedure. Experience in working with the equipment and reading the results plays a major role. However, if spectra averaging could be employed by taking many spectra from the sample (30-40) and combining them into one average, many of the difficulties would be eliminated. As with the burn depth profiles, a computer system would greatly facilitate the averaging process. With the aid of a computer, the phase shift in the attenuation measurements could be determined and taken into account when calculating tissue attenuation. Future experiments will be computer-based.

Two objectives were under study in this thesis: to define accurately burn depths in skin and to characterize normal and burn tissue using high resolution ultrasonic techniques. It was determined that the depth of a burn could be identified readily using ultrasonics. Also, several tissue characteristics, density and attenuation, effecting the tissue's capability to produce an ultrasonic echo were established. Improvements are still to be made, but the techniques have been proven effective. 

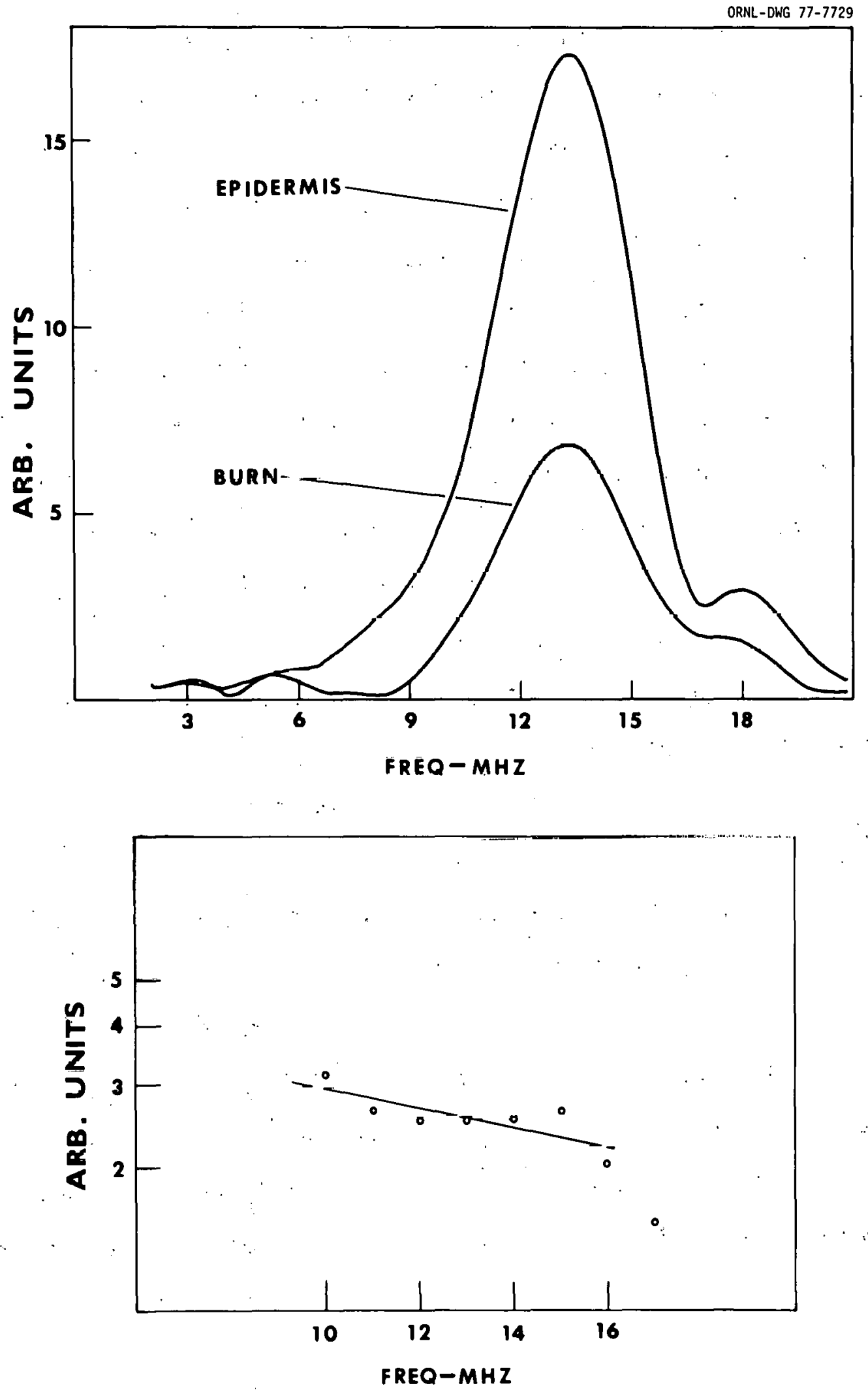

Figure 30. Frequency Spectrum -- Burned Tissue. 
CHAPTER VI

FUTURE USE

An extension of the depth measurements in tissue and the tissue characterization using spectrum analysis can readily be made into a field of medicine which at the present time is under considerable public and professional scrutiny. Screening for breast cancer using $x$-ray mammography has been effective in identifying tumors (Ma75) but has also been criticized for being the primary cause of cancer later in life. A literature search concerning ultrasonic breast imaging (La66, Ge74, Fr72, De69, Ho54, Wi52) shows that the present resolution capability for determining breast lesions is on the order of 1 to $1.5 \mathrm{~cm}$ (Da70, We69). With the system described in this thesis, the resolution can be improved by approximately a factor of 2 to 3 , thereby making high resolution ultrasonic scanning an effective tool in breast cancer screening. It is believed that tumors on the order of $0.5 \mathrm{~cm}$ or less could be detected without the problems attendant to use of ionizing radiation. An initial study utilizing rat tumors is described in Appendix I. 
APPENDIX I.

TUMORS

- In a preliminary study. of tumor imaging using high resolution ul.trasonic techniques, rats were the experimental subjects. The tumors were spontaneous cancers of the rat mammary glands immediately below the skin and superficial to the rest of the body. Al though large in size (one being approximately $2.5 \mathrm{~cm}$ in diameter and $1.5 \mathrm{~cm}$ in thickness), it was determined that the tumors would be suitable for initial observations of the tumor by 47 trasonic scans.

For each experiment, the rat was anesthesized with Methofane, an inhalation anesthetic. The hair on the skin over the tumor was shaved, and a comrnercial gel. served as the acoustic coupling agent between skin and transducer. The ultrasonic equipment and transducers described in Chapter IV were utilized for this work. But, it was observed that a mirroring effect, reflections echoing within the delay line, was interfering with the reflections from the tumor. This effect occurred in the scans at multiple lengths of the delay line and corresponded to the dimensions of the tumor. Therefore, another delay line of glass tubing, this one having an inside diameter of $3.7 \mathrm{~cm}$ and a length of $3 \mathrm{~cm}$, was designed and successfully implemented.

After the rat was anesthesized and shaved, scans were taken at several points and from several directions. The tumor center, top, bottom, right and left of center were scanined from the skin toward the body of the rat. Then, scans from the right side of the tumor toward 
the left side and vice versa were made. Figure 31 is typical of the data collected. Both views of this figure show the center of the tumor looking from skin to body. View A, with $1 \mathrm{~mm} /$ div, clearly shows the tumor to be in the middle of the scan and non-homogeneous. View B, with $5 \mathrm{~mm} /$ div, also clearly outlines the tumor. Additionally, View B distinguishes sub-tumor structures, such as the muscle immediately below the tumor. Interesting to note was that scans taken from the two side directions correlated well for the location of tumor structures.

Without sacrificing the rat, the tumor was removed, scanned again, and then dissected. The second set of scan data for the tumor was very similar to the set of data obtained before excision. The dissection of the tumor proved to be very interesting. Fibrous tissue was prevalent throughout and usually made up one hard nodule within the tumor. Soft cancerous tissue formed the remainder of the tumor. Therefore, it became obvious why there were multitudinous reflections from inside the tumor. The soft tissue was homogeneous, causing no echos. The fibrous tissue caused the non-homogeneity in the scans.

Thus, in a preliminary study, tumors in rats were ultrasonically scanned and studied. The high resolution of the system, $\sim 0.2 \mathrm{~mm}$, enabled tumor structure to be discernible, and the structure below the tumor identifiable. In future studies, however, it will be necessary to utilize smaller tumors and preferably those not visible to the observer. This will be required to fully test the high resolution ultrasonic techniques in tumor scanning. As in burn depth determination, two-dimensional scans 

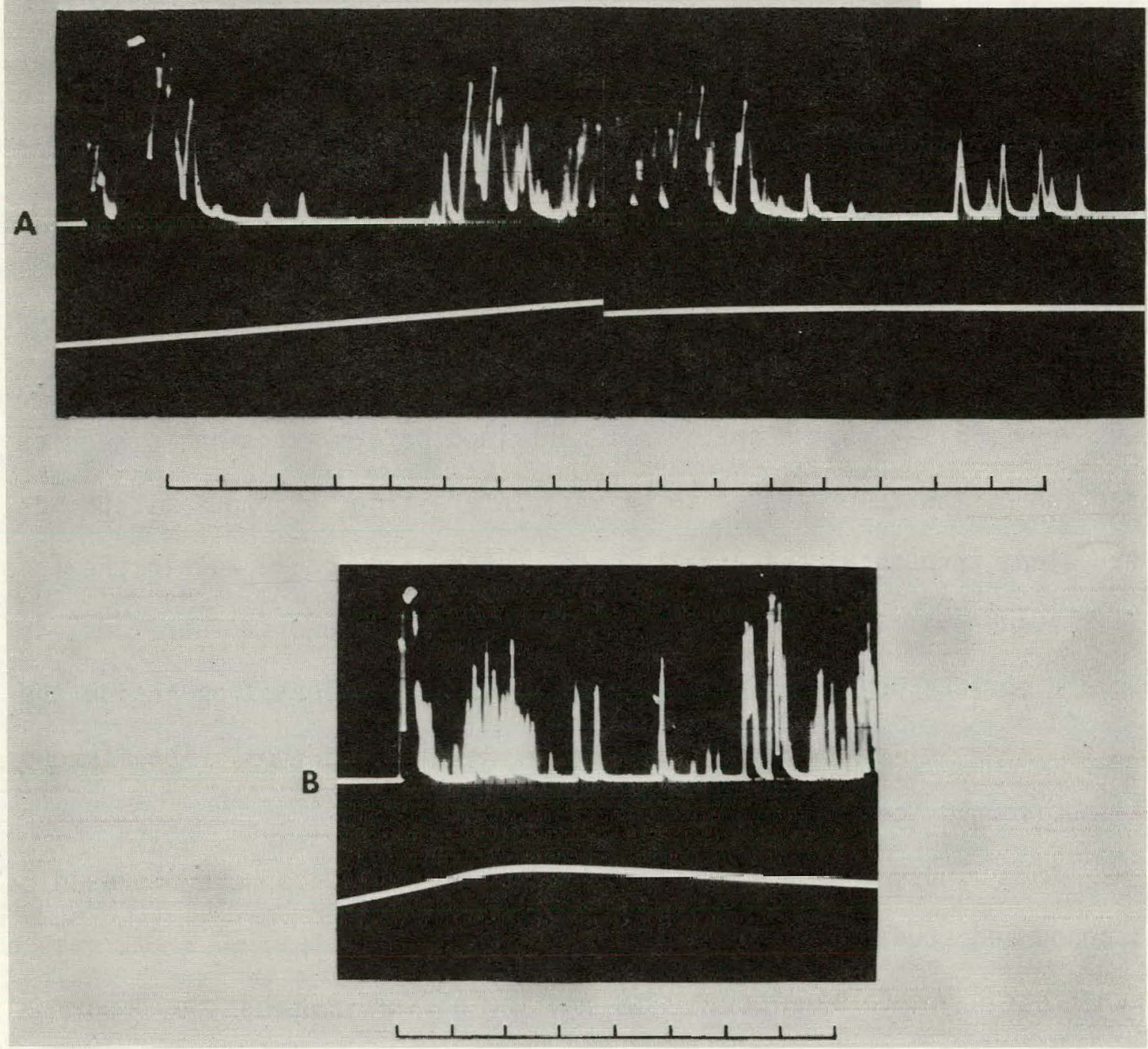

Figure 31. Ultrasonic Scan of Rat Tumor. a. $1 \mathrm{~mm} / \mathrm{div}$. b. $5 \mathrm{~mm} / \mathrm{div}$. 
will be necessary, as will be computer utilization. Also of important interest is the tumor characterization using spectrum analysis. Due to limited time, however, none of the above suggested experiments could be performed for this thesis. 


\section{LITERATURE CITED}

Ar73 Curtis P. Artz, Dabney R. Yarbough, III. "Major Body Burn." JAMA, March 19, 1973, Vol. 223, No. 12.

Bu74 John F. Burke, Conrado C. Bondoc, William C. Quinby. "Primary burn excision and immediate grafting: a method shortening illness." Journal of Trauma, May 1974, Vol. 14, No. 5.

Ca76 John H. Cantrell, Jr.; Ronald E. Goans. "Acoustic impedance variations at burn-nonburn interfaces in porcine skin." Submitted to Journal of the Acous. Soc. of America.

Da70 Rruno Damascelli, Renato Musumeci, Serglo Orefice. "Sonar İnformation About Breast Tumors." Radiology, September 1970, 96.

De69 Frank H. DeLand. "A modified technique of ultrasonography for the detection and differential diagnosis of breast lesions." Amer. J. Roentgen, February 1969, Vol. 105, No. 2.

Fr72 Elizabeth Kelly Fry, George Kossoff, Homer A. Hindman, Jr. "The potential of ultrasound visualization for detecting the presence of abnormal structures within the female breast." 1972 U1trasonics Symposium Proceedings, 1972.

Ge74 Phyllis George. "Swellings of the Breast." The Practitioner, February 1974, Vol. 212.

Go76 Ronald E. Goans, John H. Cantrell, Jr., F. Bradford Meyers. "Ultrasonic pulse-echo determination of thermal injury in deep dermal burns." Submitted to Medical Physics.

Go77 Ronald E. Goans, persnnal communication, March 1977.

Ho54 Douglass H. Howry, Dorothy A. Stott, W. Roderic Bliss. "The Ultrasonic Visualization of Carcinoma of the Breast nnd Dther Soft-Tissue Struclures." Cancer, March 1954, Vol. 7.

Hu75 Matthew Hussey. Diagnostic Jltrasound. John Wiley \& Sons, 1975.

Ka66 G. W. C. Kaye, T. H. Laby. Tables of Physical and Chemical Constants. Lorignans, Green \& Co., Ltd., 1966.

Ki50 Lawrence E. Kinsler, Austin R. Frey. Fundamentals of Acoustics. John Wiley \& Sons, Inc., 1950.

Kn74 Francis S. Knox, III, George R. McCahau, Jr., Thomas L. Wachtel. "Use of the.Pig as a Bioassay Substrate for Evaluation of Thermal Protective Clothing and Physical Sensor Calibration." Aerospace Medicine, August 1974. 
La66 Erkki Laustela, Teuvo Kerminen, Juho Lieto, Pekka Tala. "Studies of the Ultrasonic Diagnosis of Breast Tumors." Annales Chirurgiae et Gynaecologiae Fenniae, 1966:55.

Li76 F. Lizzi, L. Katz, L. St. Louis, D. J. Coleman. "Applications of spectral analysis in medical ultrasonography." Ultrasonics, March 1976.

Lu50 George D. Ludwig. "The velocity of sound through tissues and the acoustic impedance of tissues." Journal of the Acous. Soc. of America, November 1950, Vol. 22, No. 6 .

Ly73 Edited by J. B. Lynch, Stephen R. Lewis. Symposium on the Treatment of Burns, C. V. Mosby Company, 1973.

Ma75 John E. Martin, H. Stephen Gallager. "Reflections on Benign Disease: A Radiographic-Histologic Correlation." Early Breast Cancer. Edited by H. Stephen Gallager. John Wiley \& Sons, 1975.

Me77 "Does the U.S. need more burn care facilities?" Medical World News, January 24, 1977.

MIRD 69 Medical Internal Radiation Dose Committee. W. S. Snyder, M. R. Ford, G. G. Warner, and H. L. Fisher, Jr. "Estimates of Absorbed Fractions for Monoenergetic Photon Sources Uniformly Distributed in Various Organs of a Heterogeneous Phantom." Journal of Nuclear Medicine, Suppl. No. 3, August 1969, Vol. 10.

Mo63 William Montagna, Jeung S. Yon. "The skin of the domestic pig." Journal of Investigative Dermatology, 1963.

Ro54 Stephan Rothman; M.D. Physiology and Biochemistry of the Skin. University of Chicago Press, 1954.

Se7l William W. Seto. Acoustics. McGraw-Hill Book Company, 1971.

Si74 W. A. Simpson, Jr. "Time-frequency-domain formulation of ultrasonic frequency analysis." Journal of the Acoust. Soc. of America, December 1974, Vol. 56, No. 6.

St76 Harry S. Stambaugh, M.D., personal communication, November 1976.

Vi73 Claude A. Villee, Warren F. Walker, Jr., Robert D. Barnes. General Zoology. W. B. Saunders, 1973.

Wa73 Thomas L. Wachtel, G. R. McCahan, Jr. "Porcine Burn Shock." USAARL Report No. 73-12, June 1973. 
We69" P. N. T. Wells. Physical Principles of Ul.trasonic Diagnosis. Academic Press, Inc., Ltd., (London), 1969.

We72 Peter N. T. Wells, editor, Ultrasonics in Clinical Diagnosis. Churchill Livingston, 1972.

Wi52 John J. Wild, John M. Reid. "Further Pilnt Echographic Studies on the histologic structure of tumors of the living intact human breast." The Amer. Journal of Pathology, 1952, Vol. 8. 


\section{LITERATURE UNCITED}

Charles R. Baxter. "The Current Status of Burn Research." Journal of Trauma, January 1974, Vol. 14, No. 1.

R. C. Chivers, C. R. Hill. "A Spectral Approach to U1trasonic Scattering from Human Tissue: Methods, Objectives and Backscattering Measurements." Phys. Med. Biol., 1975, Vol. 20, No. 5.

Sir. Howard W. Florey, Editor. General Pathology. W. B. Saunders Co., 1958.

F. C. Henriques, Jr., A. R. Moritz. "Studies of thermal injury, I. The conduction of heat to and through skin and the temperatures attained therein. A theoretical and an experimental investigation." Amer. J. Path., 1947, Vol. 23.

J. B. Lynch. "Thermal Burns." Plastic Surgery. Edited by William C. Grabb, James W. Smith. Little, Brown and Co., 1973.

R. A. Willis. Pathology of Tumors. Butterworth and Co., Ltd., 1948. 


\section{THIS PAGE WAS INTENTIONALLY LEFT BLANK}


ORNL/TM-5934

\section{INTERNAL DISTRIBUTION}

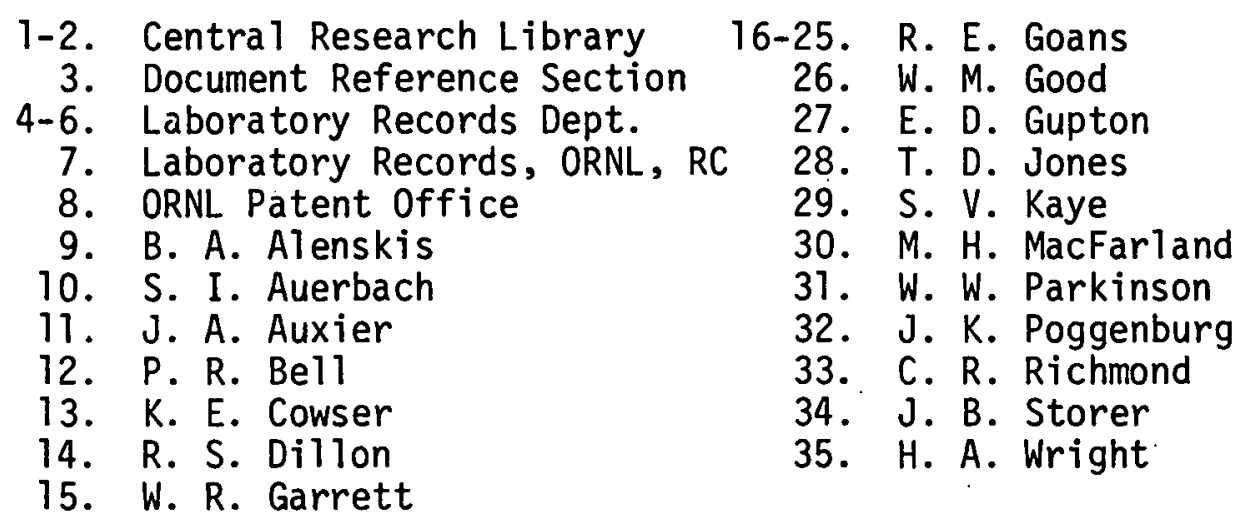

\section{EXTERNAL DISTRIBUTION}

36. Louis Assini, Mechanical Engineering, RPI, Troy, NY 12181.

37-39. John H. Cantrel1, Jr., 123J Windsor Castle Drive, Newport News, VA 23602.

40. J. C. Corelli, Nuclear Engineering Department, RPI, Troy, NY 12181 .

41. G. G. Eichholz, School of Nuclear Engineering, Georgia Institute of Technology, Atianta, GA 30332.

42. G. R. Eisele, UT-CARL, 1299 Bethel Valley Road, Oak Ridge, TN 37830.

43-44. G. C. Kyker, Oak Ridge Associated Universities, P. 0. Box 117, Oak Ridge, TN 37830.

45-47. John W. Poston, School of Nuclear Engineering, Georgia Institute of Technology, Atlanta, GA 30332.

48. Research and Technical Support Division, Oak Ridge Operations, Oak Ridge, TN 37830

49. Donald Rodbe11, Biomedical Engineering, RPI, Troy, NY 12181.

50. Marvin Rosenstein, Bureau of Radiological Health, Food and Drug Administration, 12720 Tw1 nbrook Parkway, Rockville, MD 20852.

51-61. Roberta L. Roswe11, c/o Andrew J. Rapacz, 777 McMurray \#6, Richl and, WA

62. Robert H. Ryan, Nuclear Engineering Department, RPI, Troy, NY 12181.

63. Harry D. Stambaugh, Suite 3-E, Suburban Medical Plaza, Dutchman's Lane, Louisville, KY 40207.

64. Paul Stansbury, Department of Environmental Sciences and Engineering, School of Public Health, University of North Carolina at Chapel Hill, Chapel Hill, NC 27514.

65-91. Technical Information Center, Oak Ridge, TN 37830.

92. H. E. Walburg, UT-CARL, 1299 Bethel Valley Road, Oak Ridge, TN 37830 .

93. W. W. Weyzen, Division of Biomedical and Environmental Research, Energy Research and Development Administration, Washington, DC 20545.

94. R. W. Wood, Division of Biomedical and Environmental Research, Energy Research and Development Administration, Washington, DC 20545. 